\title{
LO MISMO, LO OTRO, LO ANÁLOGO. COSMOLOGÍA Y CONSTRUCCIÓN HISTÓRICA A PARTIR DEL REGISTRO ICONOGRÁFICO SANTAMARIANO
}

\section{THE SAME, THE OTHER, THE ANALOGUE. COSMOLOGY AND HISTORICAL CONSTRUCTION BASED ON SANTA MARÍA ICONOGRAPHIC SOURCES}

\section{Javier Nastri* \& lucila Stern Gelman**}

Las urnas funerarias santamarianas, producidas por la sociedad calchaquí entre los siglos XI y xVII de la Era, se caracterizan por la repetición de un personaje antropomorfo denominado "figura de las largas cejas". El presente trabajo ofrece un análisis iconográfico de carácter comparativo sobre una muestra extensa de piezas, centrado en el estudio de urnas con una decoración anómala en la figuración habitual. La comparación se establece con especímenes materiales de adornos faciales y su representación icónica en los Andes centrales y el Noroeste Argentino. A partir de los modelos de lo Mismo, lo Otro y lo Análogo se propone que lo representado en los cuellos de las piezas corresponde a referentes reales de ornamentos faciales y adornos cefálicos, usados en el pasado por personas ocupantes de roles específicos en la sociedad en cuestión.

Palabras clave: urnas funerarias, iconografía, cosmologías, analogía, ornamentos faciales

Santa Maria funerary urns were produced by Calchaqui artisans between the eleventh and seventeenth centuries. Many of these urns display an anthropomorphic being called "the figure with long eyebrows." The article offers a comparative iconographic analysis of an enormous sample of vessels that focuses on urns with atypical neck decorations. These are compared to material specimens of facial ornaments and their iconographic representations in the Central Andes and Northwestern Argentina. Based on the models of the Same, the Other and the Analogous, it is proposed that the referents of the atypical designs on the necks of the urns are real objects: facial and cephalic ornaments worn by persons with specific roles within past societies.

Key words: Funerary urns, iconography, cosmologies, analogy, facial ornaments
La arqueología de los pueblos precolombinos es inherentemente antropológica, en la medida en que implica el enfrentarse a una alteridad cultural muy distante del marco cognoscitivo del investigador. No deja por esto de ser histórica; primero porque el carácter diacrónico es definitorio de la disciplina, y segundo, porque el enfrentamiento a la alteridad cultural constituye también una circunstancia propia de la investigación histórica. En el presente trabajo nos proponemos reflexionar acerca de los problemas que se presentan en el estudio del registro iconográfico de una sociedad iletrada del pasado, atendiendo a la diferencia cultural en términos de ontologías de la praxis -totemismo, animismo, naturalismo, analogismo- (Descola 2006) y a las estrategias de construcción histórica en función del tipo de relación -identificación, distancia, analogía- que se establece con ese pasado (Ricoeur 1995).

Los calchaquíes se extendieron por un vasto territorio de la Subárea Valliserrana del actual Noroeste Argentino (NOA) (fig. 1), entre los siglos XI y XVII de la Era, siendo los productores de las urnas funerarias conocidas como santamarianas. Fragmentos de estas piezas cerámicas decoradas abundan en la superficie de los yacimientos que contienen restos de las poblaciones en cuestión y ejemplares de piezas completas se encuentran en numerosos museos del mundo, producto de la excavación masiva de cementerios indígenas entre fines del siglo xIx y comienzos del xx. Hemos conformado una

* Javier Nastri, Universidad de Buenos Aires / ConicET-Universidad Maimónides, Hidalgo 775, $7^{\circ}$ piso, (1405) Buenos Aires, email: nastri.javier@maimonides.edu

* Lucila Stern Gelman, Fundación de Historia Natural "Félix de Azara", Hidalgo 775, $7^{\circ}$ piso, (1405) Buenos Aires, email: lucilastern@gmail.com

Recibido: octubre de 2010. Aceptado: noviembre de 2011. 


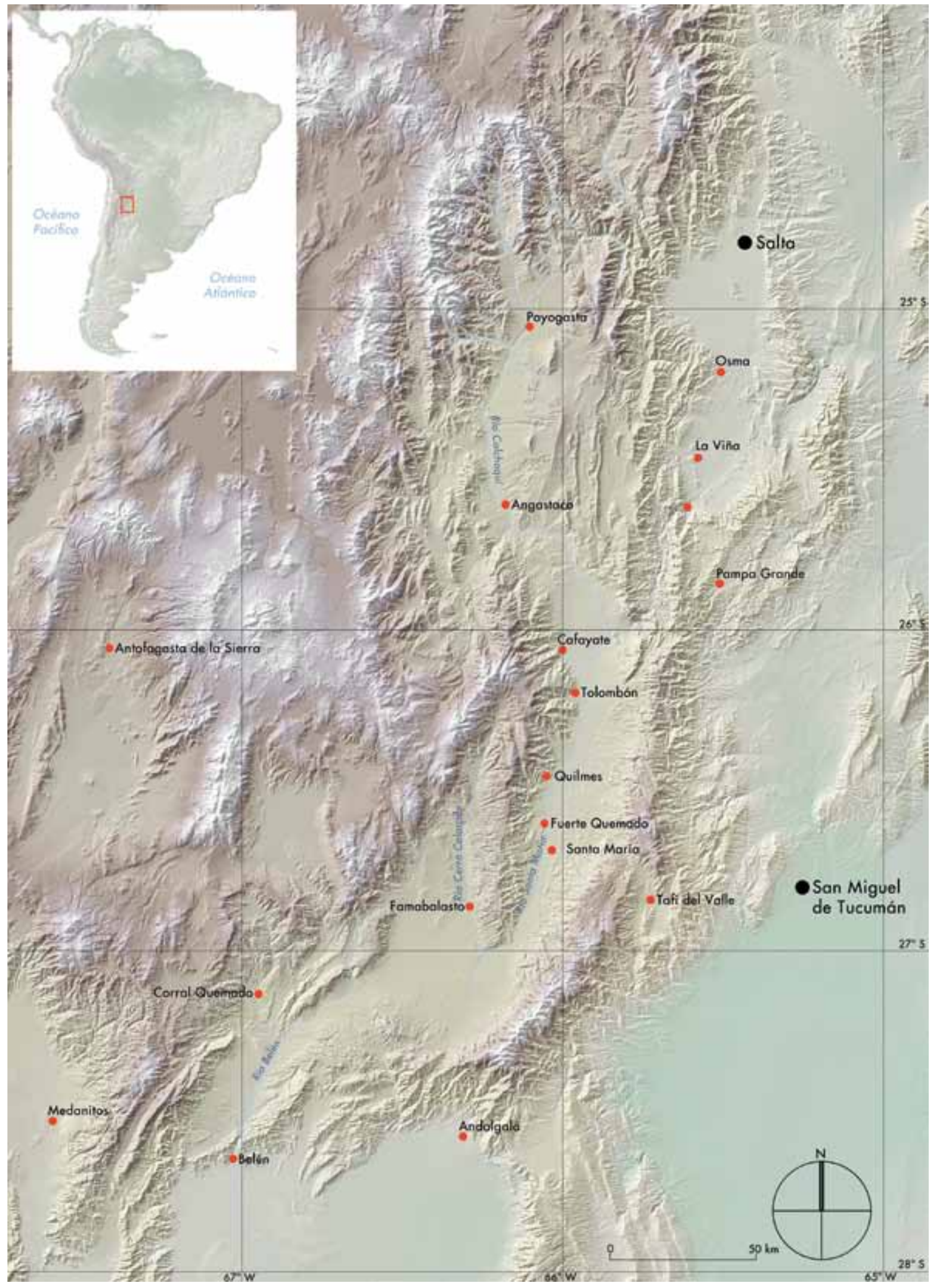

Figura 1. Mapa de la región de estudio con indicación de algunas de las localidades de donde proceden las urnas santamarianas incluidas en la muestra analizada.

Figure 1. Map of the region studied indicating some localities where the Santa Maria urns analyzed in the sample were discovered. 
muestra de 825 ejemplares depositados en distintos museos de Argentina, Europa y Estados Unidos, en la cual se destaca la repetición de un personaje antropomorfo que hemos dado en llamar figura de las largas cejas (Nastri 2008). El carácter antropomorfo del ser en cuestión resulta particularmente atractivo considerando la problemática del modo de identificación de la sociedad calchaquí, pues en la representación plástica de la humanidad puede esperarse encontrar pistas sobre la cosmovisión de la sociedad; esto es: "la aproximación existencial que el indígena tiene acerca de la totalidad que lo rodea -incluyendo al universo-, así como las formas que adoptan el hombre y la comunidad para relacionarse con él" (Martínez Sarasola 2004: 24), la cual se encuentra articulada con alguna de las ontologías de la praxis definidas por Descola (2006). No obstante, la interpretación de las mencionadas pistas es compleja, pues el sentido de las imágenes es dependiente de los contextos de uso, los cuales, además de ser en buena medida desconocidos, a su vez pudieron variar a lo largo del tiempo y del espacio. ${ }^{1}$ La tarea no es nada sencilla, pero como contrapartida podemos señalar el hecho de que las imágenes contienen un conjunto de información sumamente denso, cuya recuperación arqueológica en términos de prácticas reales podría demandar décadas o siglos. El desafío es, entonces, generar estrategias para poder, por un lado, reconstruir los contextos hasta donde sea posible y, por el otro, desarrollar mecanismos que permitan asignar significados pasibles de ser contrastados mediante el desarrollo de análisis hermenéuticos y la incorporación de nuevos datos. ${ }^{2}$ Este último aspecto es el que procuraremos desarrollar en las páginas que siguen.

\section{LAS URNAS SANTAMARIANAS}

La figura de las largas cejas se dispone con su cara en el cuello de la vasija y su torso en el cuerpo de la misma, no teniendo indicación clara de extremidades inferiores (Nastri 2008). Este esquema básico tiene una frecuencia del 94\% en la muestra analizada, frente a solo un 1\% de casos en los cuales en lugar del rostro se representan otras figuras (como animales enteros de perfil) y un 5\% de casos en los que hay motivos geométricos similares a los que adornan los textiles, lo cual puede interpretarse como indicación de que la cabeza de la figura de las largas cejas se representaba en esos casos cubierta por textiles (Velandia 2005: 117-118) a la manera de las momias andinas (fig. 2).

Atendiendo a la decoración de los cuerpos, un 7\% de los ejemplares de la muestra carece de la figuración habitual del torso de la figura de las largas cejas, la cual consiste en la unión de los brazos a la altura del pecho (fig. 3) o en una banda central vertical característica
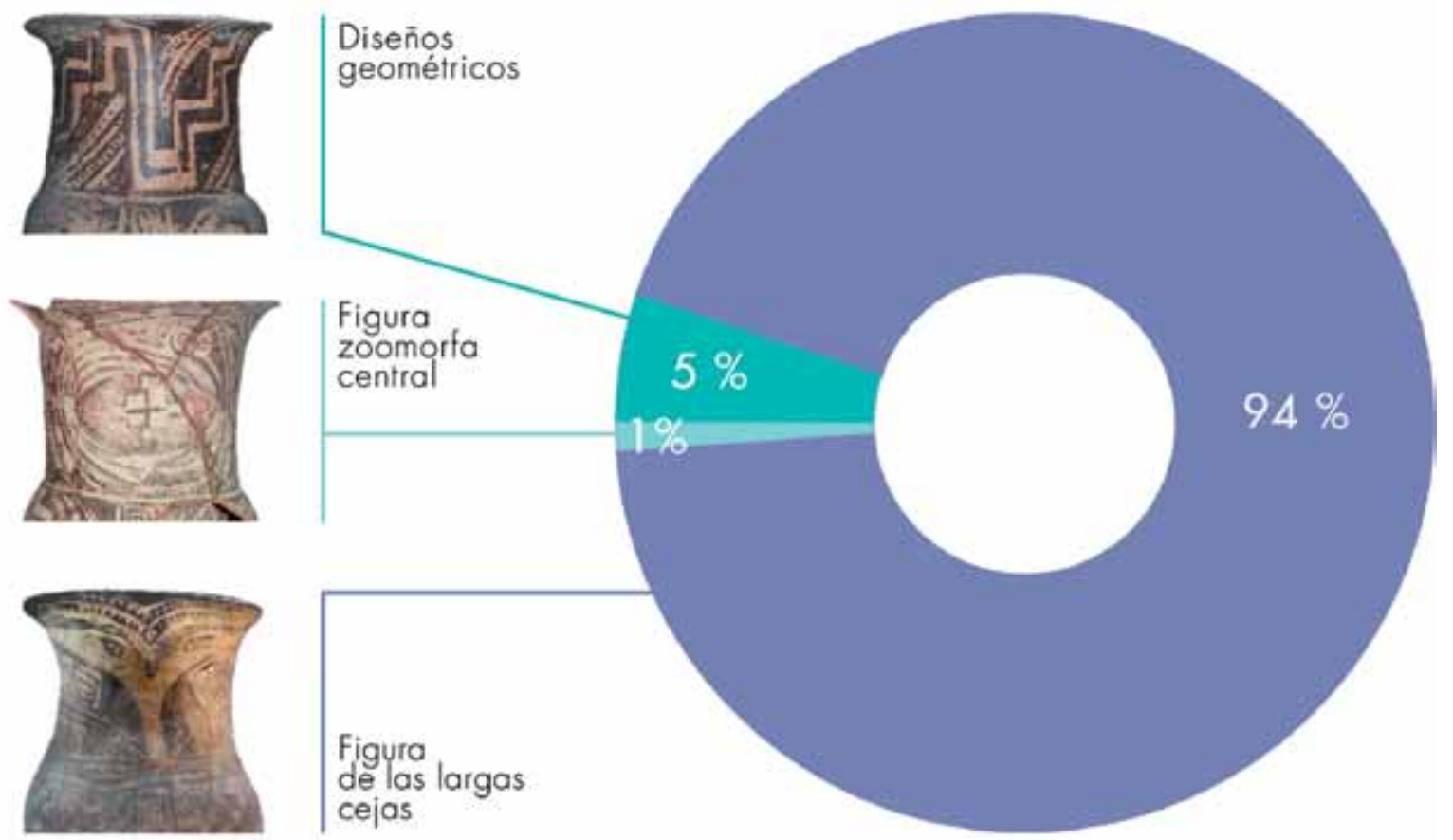

Figura 2. Frecuencia de aparición de los principales motivos en los cuellos de las urnas santamarianas.

Figure 2. Frequency of the main motifs on the necks of the Santa Maria urns. 


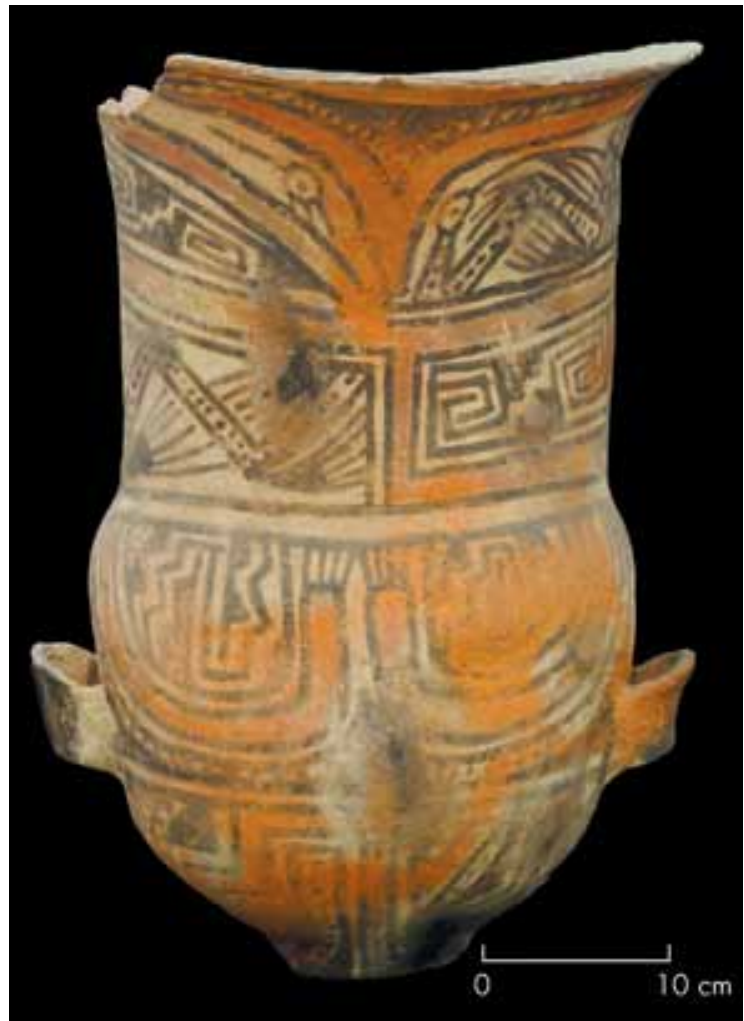

Figura 3. Ejemplo de decoración del torso de la figura de las largas cejas con brazos. Museo Etnológico de Viena, número de repositorio: 87150.

Figure 3. Example of a torso decoration of the "long eyebrows" figure, with arms. Ethnological Museum of Vienna, catalogue number: 87150.

del unku o camisa vestida por dicho personaje (fig. 4). Este pequeño conjunto de piezas atípicas presenta, en el lugar de las decoraciones habituales, una figura zoomorfa central (fig. 5) -en el $2 \%$ del total de la muestra- u otros diseños no figurativos (fig. 6) -en el $5 \%$ del total de la muestra- que hasta el momento no han sido vinculados con referente real alguno. Acerca de estos puede decirse que, siendo mayoritariamente de carácter geométrico, probablemente representen otro tipo de vestimenta (manta envoltorio en lugar de camisa) o de diseño textil de la prenda usada por la figura de las largas cejas.

De aquí en más nos concentraremos en el grupo que presenta inequívocamente este referente, en la medida en que es el mayoritario y que su carácter antropomorfo le proporciona al conjunto una estabilidad de significación en el contexto de los rituales mortuorios y vida cotidiana calchaquí. Dicha estabilidad o recurrencia facilita la asignación de significados, más allá de las posibles variaciones producto de decisiones exclusivamente autónomas de artistas individuales.

\section{EL ESTUDIO DEL SIMBOLISMO DE LAS URNAS}

Puede advertirse que a lo largo del tiempo la actitud de los arqueólogos en relación con el potencial informativo de la iconografía de las urnas ha sido variable. Ameghino (1881) interpretó a fines de la década de 1870 a los motivos antropomorfos claramente reconocibles en el cuello de las vasijas en términos de representación de jefes y sacerdotes de la antigua sociedad que habitara los valles calchaquíes, poco después Ambrosetti y Quiroga dieron vuelo a la denominada corriente filológica (Haber 1995), con la interpretación simbólica de una gran variedad de objetos muebles y representaciones rupestres de los valles calchaquíes, entre los cuales se encontraban las urnas. Boman, en cambio, representa ya en la primera década del siglo xx, una actitud escéptica y crítica respecto de la recuperación de significados del pasado. Para este autor: "Estas producciones a menudo solo son simples ornamentos sin ninguna tendencia simbólica o mitológica" (Boman 1991: 106). Señalaba luego que el problema de la interpretación simbólica de la iconografía de las urnas residía en que los animales o figuras representadas variaban de una pieza a la otra (Boman 1991: 165). Esta variación fue tomada con miras al establecimiento de una seriación cronológica, en la década de 1970 (Podestá \& Perrota 1973; Weber 1978, 1981), pero salvo observaciones ocasionales, fue recién en años más recientes cuando se volvieron a desplegar nuevamente estudios hermenéuticos sistemáticos del simbolismo santamariano (Nastri 2009, Nastri et al. 2009). Velandia (2005) realizó la interpretación de motivos puntuales, del simbolismo general de las urnas y de estructuras de diseño en términos de oposiciones estructurales.

En nuestra investigación, partimos de la consideración del estilo santamariano y del género de las urnas en lo que respecta a rasgos temáticos, retóricos y enunciativos (Steimberg 1993). Es la recurrencia en los valores de estos tres rasgos lo que proporciona la estabilidad de significación que permite calificar un fenómeno en términos de género y de estilo (Nastri 2010); hecho que, a su vez, permite desligar el fenómeno en cuestión del capricho individual $\mathrm{u}$ ornamento insignificante que preocupaba a Boman. La figura de las largas cejas constituye una destacada recurrencia histórica que permite calificar al fenómeno de las urnas santamarianas como un género discursivo (Nastri 2010).

La dimensión temática está dada por la referencia de un texto a "acciones y situaciones según esquemas de representabilidad históricamente elaborados y relacionados, previos al texto" (Segre 1985: 48); la retórica, 


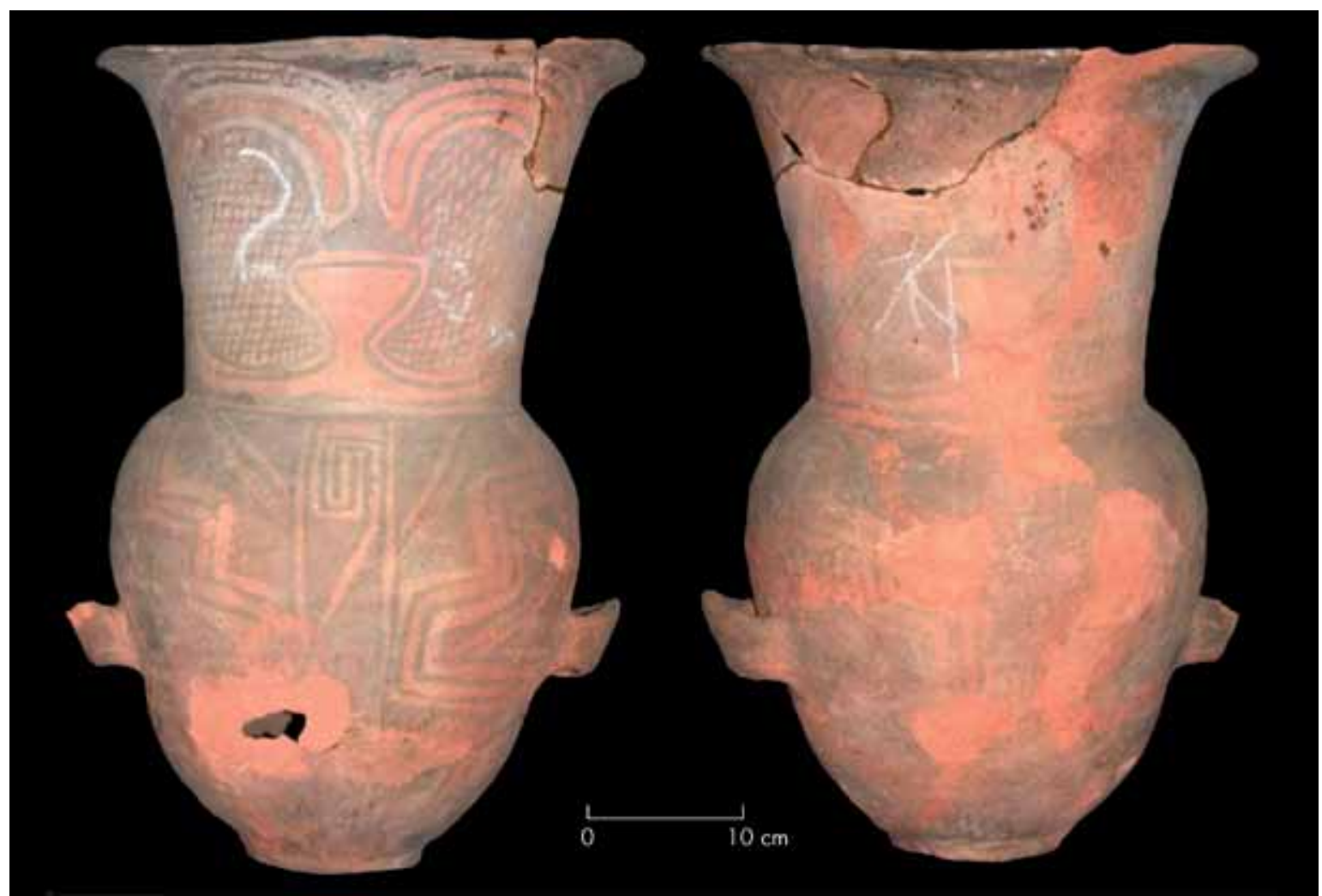

Figura 4. Ejemplo de decoración del torso de la figura de las largas cejas con banda central vertical. En el cuello, un motivo de ornamento facial. Procedente de Fuerte Quemado. Museo Etnográfico J. B. Ambrosetti (MEJBA), número de repositorio: 44-1922.

Figure 4. Example of a torso decoration of the "long eyebrows" figure with central vertical band. Note the facial ornament motif on the neck. From Fuerte Quemado. Museo Etnográfico J. B. Ambrosetti (MEJBA), catalogue number: 44-1922.

por los mecanismos de configuración de un texto (Hodder 1993); mientras que la enunciativa alude a las condiciones de la situación comunicacional (fig. 7). En las urnas es posible reconocer, desde el punto de vista temático, a la figura de las largas cejas, suris, serpientes, sapos, lagartijas y personajes humanos. Puede advertirse luego que en un gran número de casos los motivos se funden, de manera tal que cabe pensar en la posibilidad de referentes mixtos, o bien en la presencia de un particular procedimiento retórico, consistente en la alteración de la forma del motivo representado o de un extremo del mismo, de modo que adquiera la forma de o se fusione con otro de los motivos del repertorio en cuestión. Este procedimiento tiene aspectos en común con los que hace años describiera Rowe (1972) en relación con el arte Chavín, para los cuales apeló a la denominación de kennings: sustituciones por comparación; los cabellos del Lanzón Chavín de Huántar "son como serpientes". La comprensión de este y otros procedimientos realmente originales del ámbito andino requiere así de una terminología específica, tanto de acuerdo con el método de análisis a emplear como con el marco teórico de interpretación.
Por último, el uso de los colores negro, o negro y rojo, sobre fondo blanco, el trazo lineal y el abigarramiento de los motivos pintados, junto con un uso acotado de apéndices modelados, se cuentan entre las principales regularidades enunciativas del género de las urnas.

Dadas la alta frecuencia de aparición de urnas en grandes cementerios fácilmente detectables y las excavaciones masivas realizadas durante los siglos pasados, el género de las urnas santamarianas ha sido objeto de aproximaciones cuantitativas sobre muestras amplias, en el contexto de las colecciones cerámicas del NOA (Podestá \& Perrota 1973; Weber 1978; para una síntesis de las contribuciones anteriores véase Nastri 2009). Aun así, la muestra de urnas santamarianas analizada en este trabajo (825 ejemplares) multiplica varias veces el tamaño de cada una de las trabajadas anteriormente. Apelamos para su análisis al método comparativo de Lévi-Strauss (1958), empleado en su estudio inaugural de los mitos. En el mismo, los sucesos que se disponen diacrónicamente para conformar la historia mítica (primera dimensión) son colocados en columnas determinadas (segunda dimensión), en función "de un rasgo común que se trata de descubrir" (Lévi-Strauss 1958: 194). Estos 


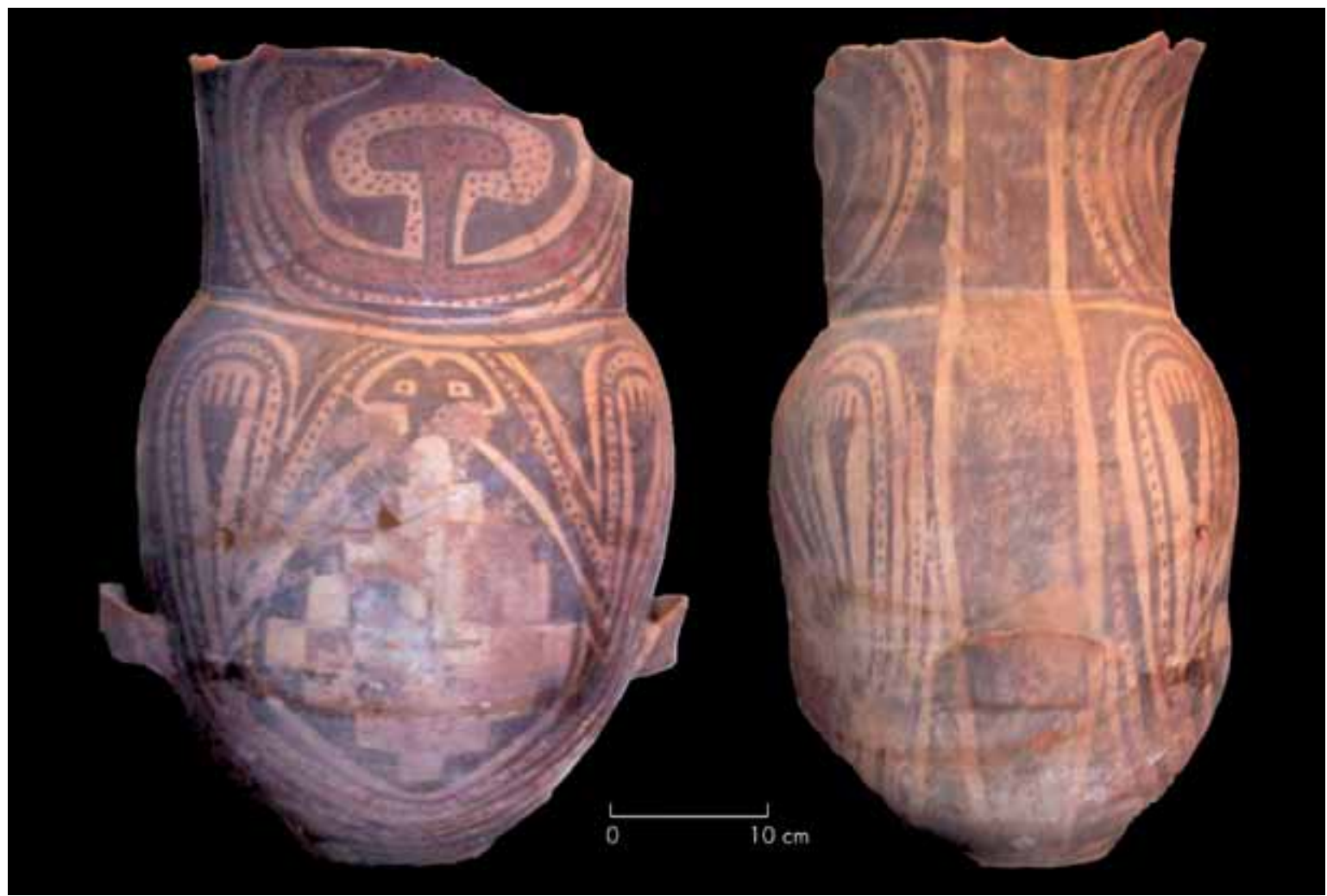

Figura 5. Ejemplo de urna con representación en el cuerpo de un motivo zoomorfo central. En el cuello, un motivo de ornamento facial. Procedencia Tafí. Museo Jesuítico Banda de Dios, sin número.

Figure 5. Example of an urn with representation of a central zoomorphic figure on the body. On the neck is a motif of a facial ornament. From Tafi. Museo Jesuitico Banda de Dios, unnumbered.

a su vez se corresponden con elementos homólogos de otras versiones del mismo mito, que constituyen la tercera dimensión (fig. 8). Dado que se trata de imágenes que responden a estrictas convenciones representativas, entre las cuales se cuentan la posición de cada motivo en los campos decorativos de la pieza, resulta innecesaria la operación de ordenamiento paradigmático de la segunda dimensión que realiza Lévi-Strauss con los mitos (aparte que nuestros objetivos interpretativos son tanto más modestos, como menos abstractos que los del célebre autor de las Mitológicas). El orden sintáctico de los motivos en el contexto de cada pieza es en rasgos generales el mismo en toda la serie, hecho que facilita la identificación de los términos homólogos para los fines de la comparación entre las piezas; esto es: la tercera dimensión del análisis.

Al igual que en el análisis estructural de los mitos, la homología de elementos entre urnas hace que el conjunto de estas se disponga como una serie de permutaciones que en sus extremos evidencian un contraste bien de carácter estructural o histórico. Para poder describir ese continuum, apelamos a la categoría de alteración, entendida como un cambio en la cualidad de una figura, que sin embargo, sigue siendo la misma (Nastri 2009). Los cabellos del Lanzón no dejan de ser cabellos, por más que muestren forma de serpiente; los ojos de la figura de las largas cejas no dejan de ser ojos, a pesar de que también pueden presentarse como cabezas de suris. La propuesta de Descola (2012) permite advertir que lo que percibimos como procedimientos retóricos tiene profunda relación con la cosmología -u ontologías de la praxis- de las sociedades en cuestión. Según dicho autor existen dos pensamientos universales en las sociedades humanas: el reconocimiento de la existencia de especies diferentes en el mundo y la conciencia de la existencia de interioridad. La combinación de los distintos valores que pueden asumir estos dos principios (en términos de similitud o diferencia) dan lugar a la existencia de cuatro modos de identificación u ontologías de la praxis: el totemismo, el animismo, el naturalismo y el analogismo. El totemismo establece una homología entre la discontinuidad de la serie de especies naturales y los grupos sociales. Esto es: hay continuidad física y de interioridad entre cada conjunto humano y su tótem, y discontinuidad entre los distintos conjuntos (Descola 2012: 347). El animismo también asigna conciencia a 


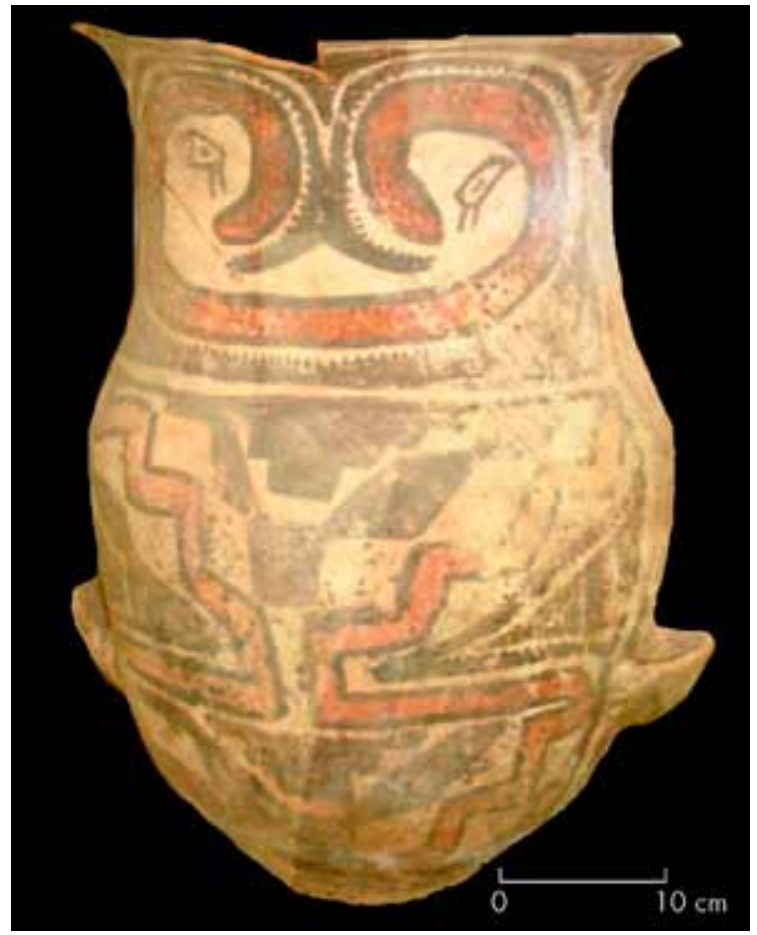

Figura 6. Ejemplo de diseño no figurativo en el cuerpo de la urna. En el cuello, representación de una nariguera semilunar. Sin procedencia. Hotel Asturias (Cafayate), sin número de repositorio. Figure 6. Example of a non figurative design on the body of an urn. On the neck is a representation of a half-moon nose ornament. Origin unknown. Hotel Asturias (Cafayate), no catalogue number.

los animales, pero no pasa por alto la diferencia entre las fisicalidades de las distintas especies. El naturalismo, propio de la sociedad europea posrenacentista, concibe a la humanidad como una más de las especies animales, estableciendo así una continuidad en este aspecto; en cambio, establece una diferencia irreductible entre la especie humana y las demás en lo que respecta a posesión de conciencia. Finalmente, el analogismo concibe una multiplicidad de diferencias en ambos planos: el de las fisicalidades y el de la conciencia. El mundo está compuesto, para esta forma de concebir el cosmos, de un sinnúmero de entidades diferentes, imposibles de ordenar. Solo resta entonces manejarse con analogías, de manera de poder comunicar las particularidades de cada entidad (Descola 1992); según el autor, este es el caso de las sociedades andinas, con lo cual puede entenderse la alta frecuencia de alteraciones en la representación de los motivos a lo largo de la serie.

\section{ORNAMENTOS FACIALES Y CEFÁLICOS EN EL ÁMBITO ANDINO}

Dispuestas las urnas a la manera "lévi-straussiana", advertimos la presencia de numerosos casos en los cuales en lugar de la representación habitual (rostro de la figura de las largas cejas) se encontraban otros motivos cuyos referentes no alcanzábamos a determinar (figs. 4, 5, 6, $9,10,11,12,13$ y 14). Comenzamos entonces a buscar análogos en objetos o representaciones de otros contextos del NOA y los Andes centrales. De este modo, detectamos sugerentes similitudes entre ornamentos faciales La Aguada, Moche e inkaicos y motivos de la iconografía santamariana (Nastri et al. 2009; Stern Gelman 2010). Una clase de dichos objetos se representan en

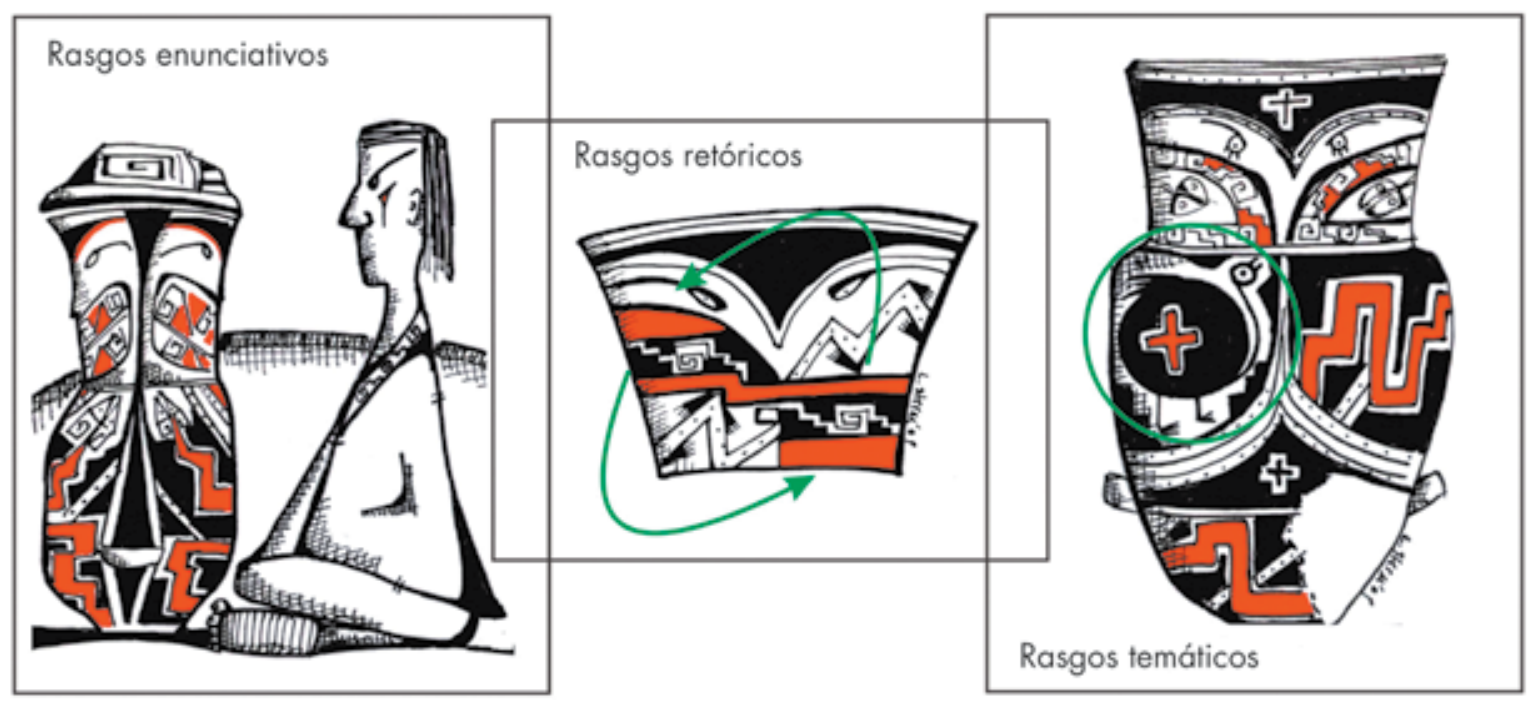

Figura 7. Ilustración de rasgos retóricos, temáticos y enunciativos (Steimberg 1993) en relación con las urnas santamarianas. Figure 7. Illustration of rhetorical, thematic and enunciative devices (Steimberg 1993) in relation to the Santa Maria urns. 


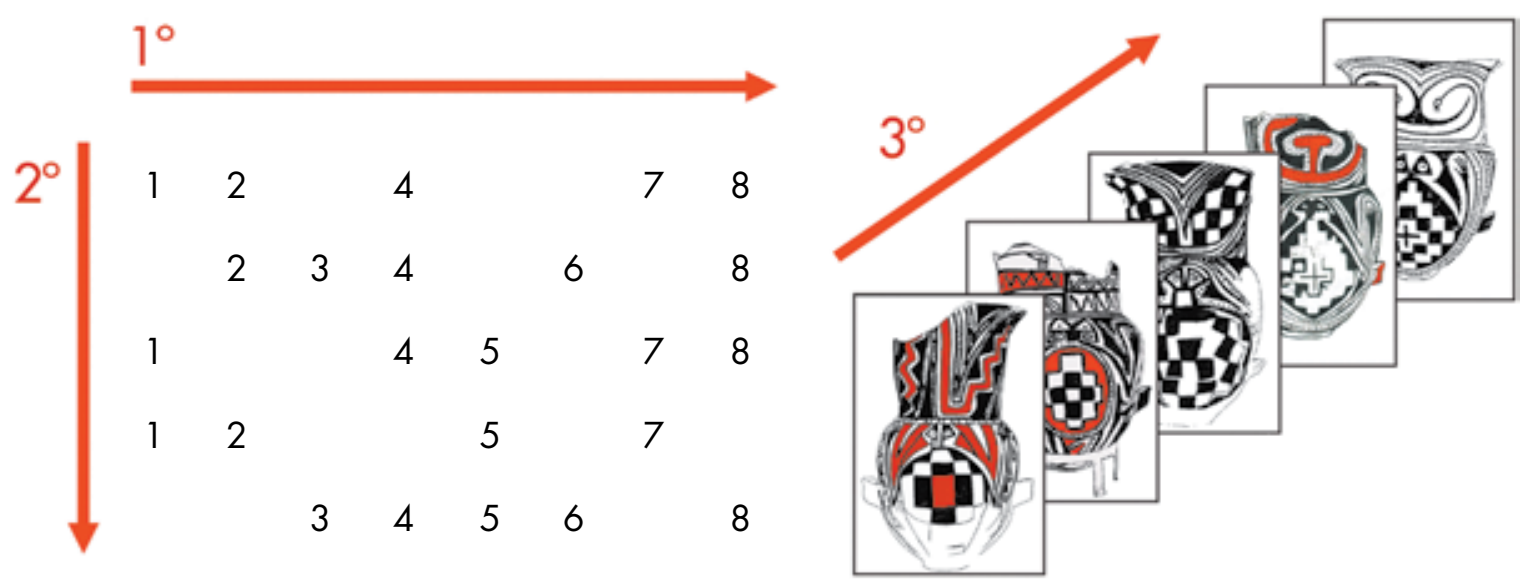

Figura 8. Adaptación del método de Lévi-Strauss para el estudio de los mitos, a las urnas santamarianas (modificado de Lévi-Strauss 1958: 193,198).

Figure 8. Adaptation of Lévi-Strauss' method of studying myths to the Santa Marian urns (based on Lévi-Strauss 1958: 193,198).

el arte santamariano invariablemente en color rojo, a veces como prolongaciones de las cejas que dan vuelta sobre ambos pómulos, o bien unidas a la altura de la boca, donde habrían estado sujetas al modo de los tembetás. En los extremos culminan frecuentemente con una representación de cabeza de serpiente, como es común en muchos casos arqueológicos del Perú y en los mencionados de la cultura de La Aguada. De modo que lo representado en las mejillas de las urnas no habría sido directamente la serpiente bicéfala, sino la mascarilla que estaba decorada en sus extremos por cabezas de serpiente.

El caso de la mascarilla procedente de la misma área de la cual proceden la mayor parte de las urnas que componen nuestra muestra -el valle de Santa María-, atribuida por González (1998: 152) a la cultura de La Aguada (fig. 15) resulta elocuente, en la medida en que existen representaciones en la cerámica que muestran una forma muy similar (fig. 16): a la manera de una letra "x" atravesada horizontalmente por una línea y con sus extremos curvados. Otras máscaras procedentes del Perú precolombino (fig. 17) tienen una orientación inversa de sus extremidades, con su concavidad hacia el interior -a las cuales denominamos perimetrales- al igual que los casos santamarianos vistos. Se trata de máscaras de boca Nasca, cuyas prolongaciones se despliegan por sobre las mejillas. Adminículos similares fueron ilustrados por Guamán Poma de Ayala (1988 [1516]; Murúa 2008 [1590]) en el siglo Xvi. En la figura 18, como atuendo de un músico y en la siguiente, como propio de jefes (fig. 19).

Otro bien metálico frecuente en contextos andinos son las narigueras (fig. 20), las cuales también cuentan con una alta representación en la muestra iconográfica considerada. Aunque no contamos con dibujos de los cronistas, Cieza de León (1932 [1553]: 85) se refiere a su uso entre la realeza inkaica:

\footnotetext{
Traen ellos y ellas abiertas las narices y puestos en ella unos que llaman caricuris que son a manera de clavos retorcidos de oro tan gruesos como un dedo, y otros más y algunos menos. A los cuellos se ponen también unas gargantillas ricas y bien hechas de oro fino y bajo, y en las orejas traen colgados unos anillos retorcidos, y otras joyas (el énfasis es nuestro).
}

Si descripciones como esta no son lo suficientemente completas para dar cuenta de la enorme variedad documentada arqueológicamente, ilustra acerca de una característica digna de destacar en relación con la evidencia santamariana: la vigencia de una técnica metalúrgica cuasi escultórica en la cual, más allá de contar con representaciones en relieve sobre planchas, las piezas también podían estar constituidas por volúmenes independientes. Resulta muy significativo el hecho de que varias representaciones con formas y proporciones similares a las narigueras arqueológicas del Perú aparecen en el rostro de la figura de las largas cejas, con trazados reticulados. Las formas pueden estar dispuestas a veces de manera diferente, pero se trata en definitiva de contornos muy parecidos, que cuentan con el reticulado representativo del enrejado. Las narigueras se representan invariablemente en color negro.

Las narigueras pueden ser de forma circular, como en los casos del Perú (fig. 20) y otros de momentos previos al Período Tardío en el NOA. En ocasiones, los vasos Condorhuasi contaban con tembetás, orejeras y narigueras "reales", esto es, confeccionadas independientemente a partir de algún otro material (que lamentablemente no se ha conservado) e insertas mediante perforaciones o bien figuradas con pintura amarilla (fig. 21), lo que hace suponer que eran de oro o bronce. Pero la variedad 


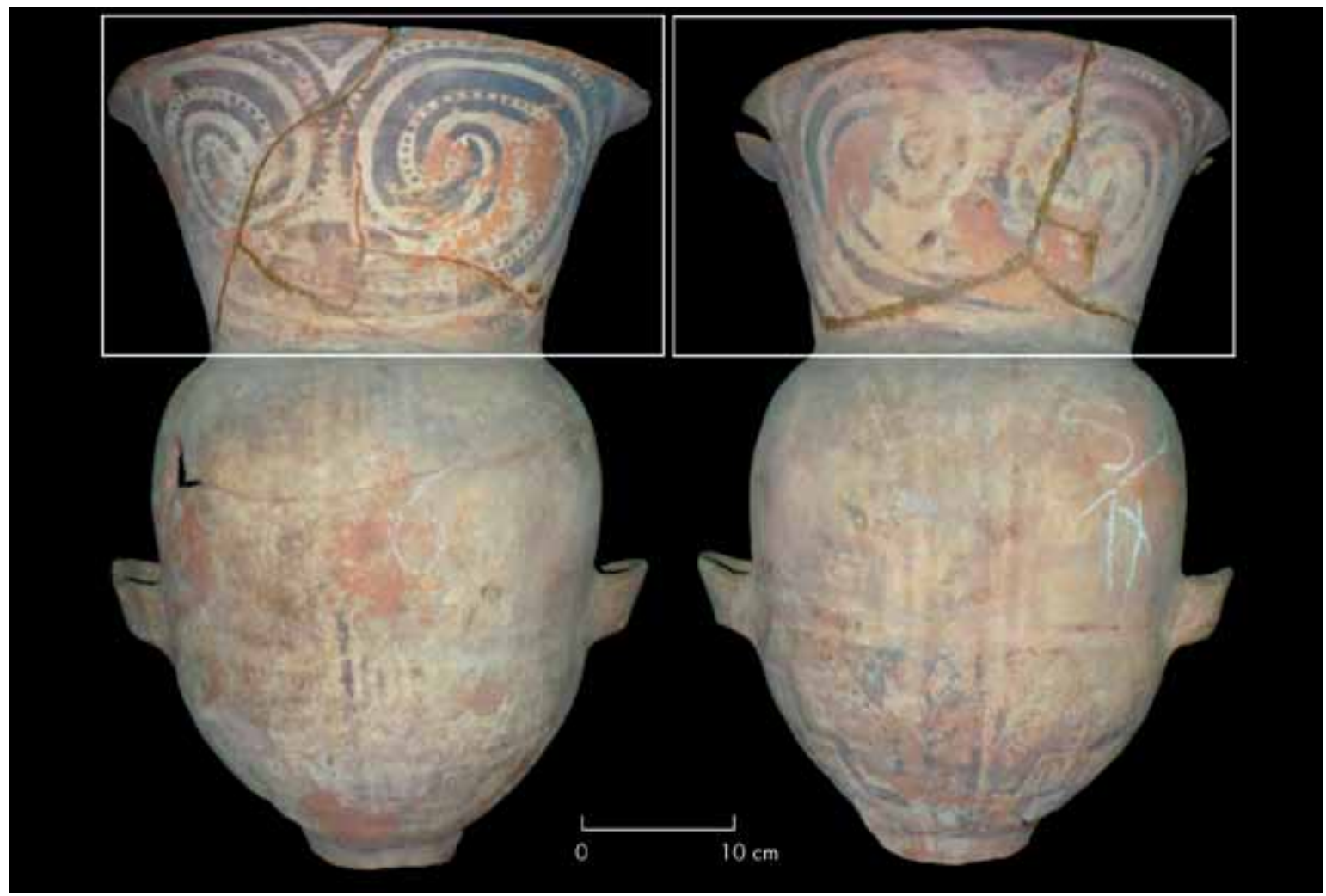

Figura 9. Ejemplo de urna con representación en el cuello de un motivo de ornamento facial: pieza número 1075 (p1075). Procedencia desconocida. MEJBA, número de repositorio: 73-223.

Figure 9. Example of an urn with facial ornament motif on the neck: piece number 1075 (p1075). Unknown origin. MEJBA, catalogue number: $73-223$.

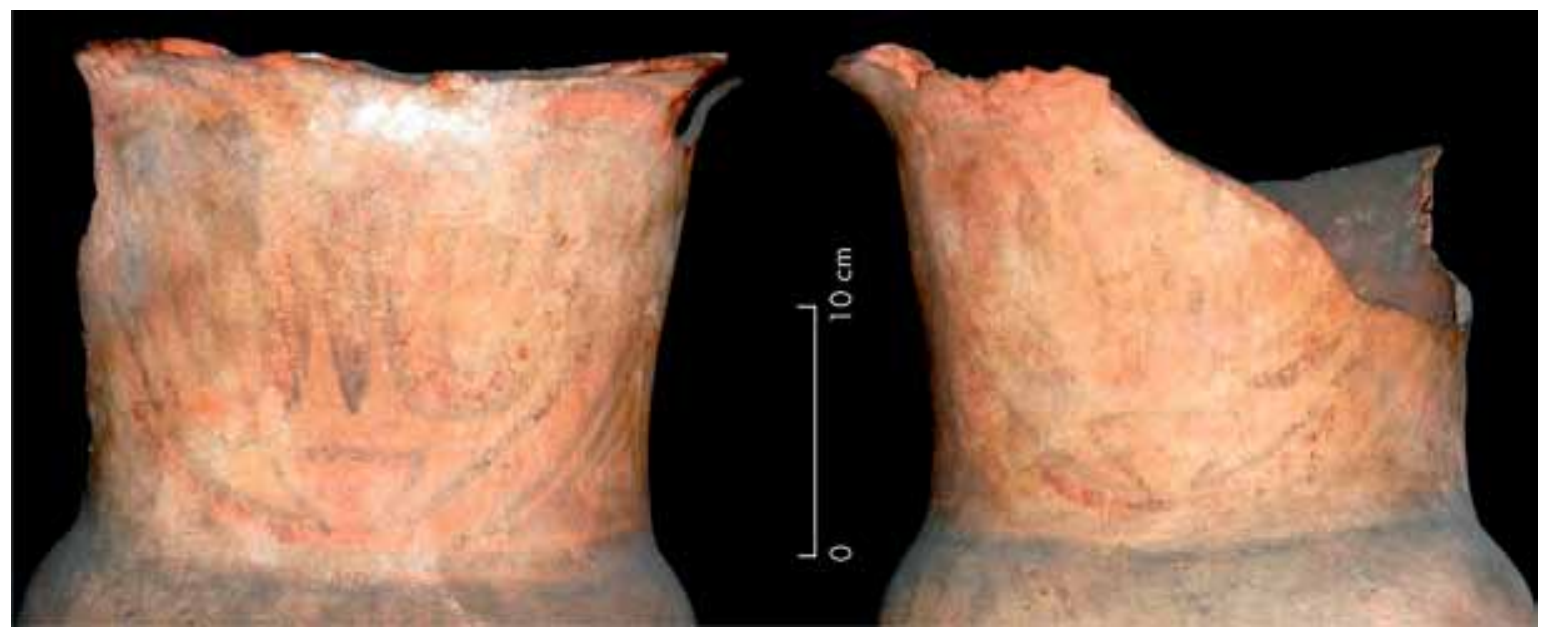

Figura 10. Ejemplo de urna con representación en el cuello de un motivo de ornamento facial. MEJBA, sin número de repositorio. Figure 10. Example of an urn with facial ornament motif on the neck. MEJBA, no catalogue number.

mejor representada en las urnas santamarianas no es esta, sino otras dos. En primer lugar la transversal, consistente en ramificaciones alargadas que se disponen hacia los laterales de la nariz (figs. 22 y 23); la cual también tiene posibles antecedentes en piezas La Aguada. La otra variedad -más frecuente en Santa María- es la semilunar (fig. 24), la cual ha sido documentada en diversos contextos culturales andinos, entre los cuales cabe destacar Moche (fig. 25). En los valles calchaquíes se han recuperado numerosos objetos de bronce con 


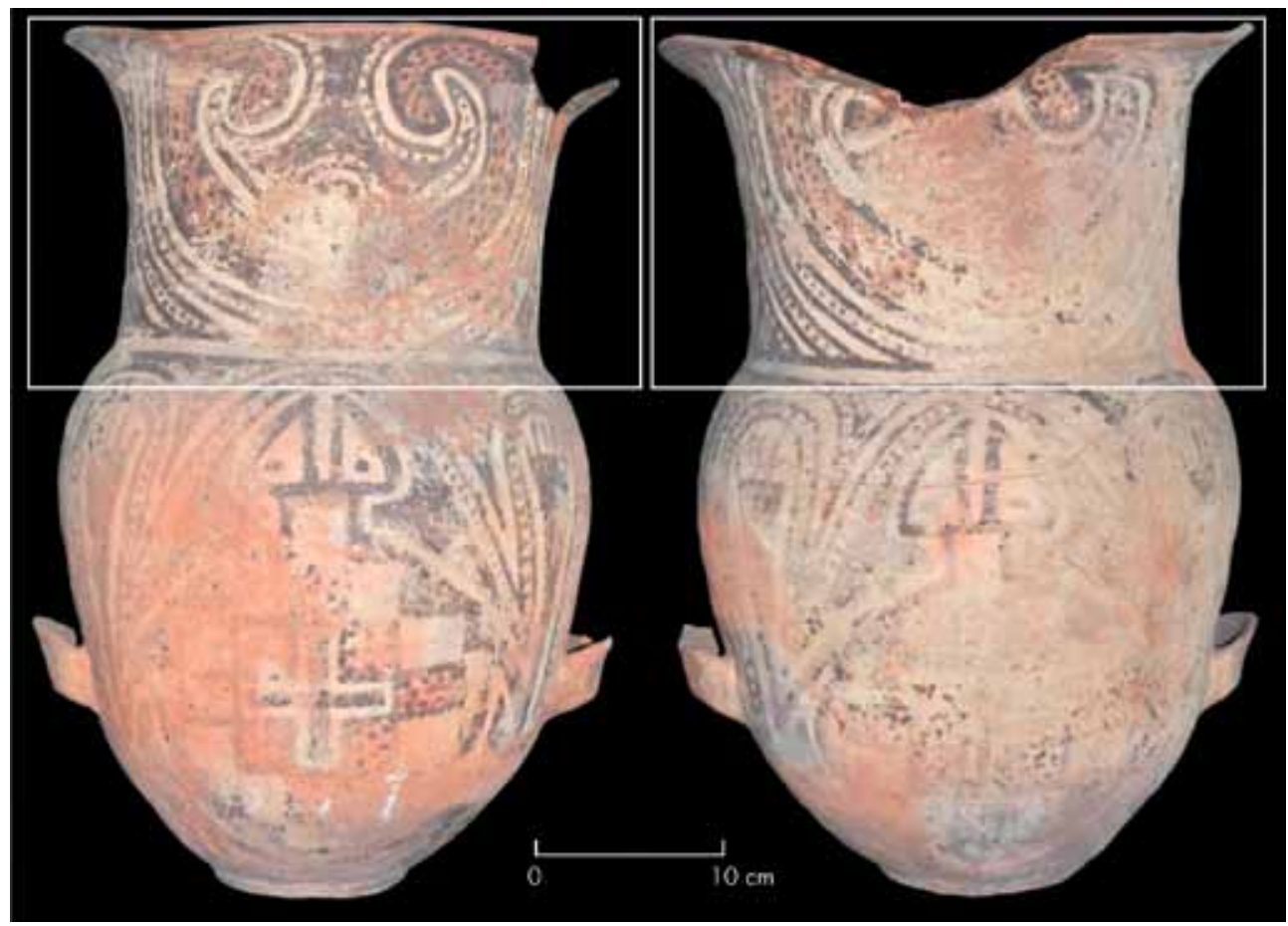

Figura 11. Ejemplo de urna con representación en el cuello de un motivo de ornamento facial. Procedente del valle de Yocavil. MEJBA, número de repositorio 8797 (ex colección Quiroga).

Figure 11. Example of an urn with facial ornament motif on the neck. From the Yocavil Valley. MEJBA, catalogue number 8797 (formerly of the Quiroga Collection).

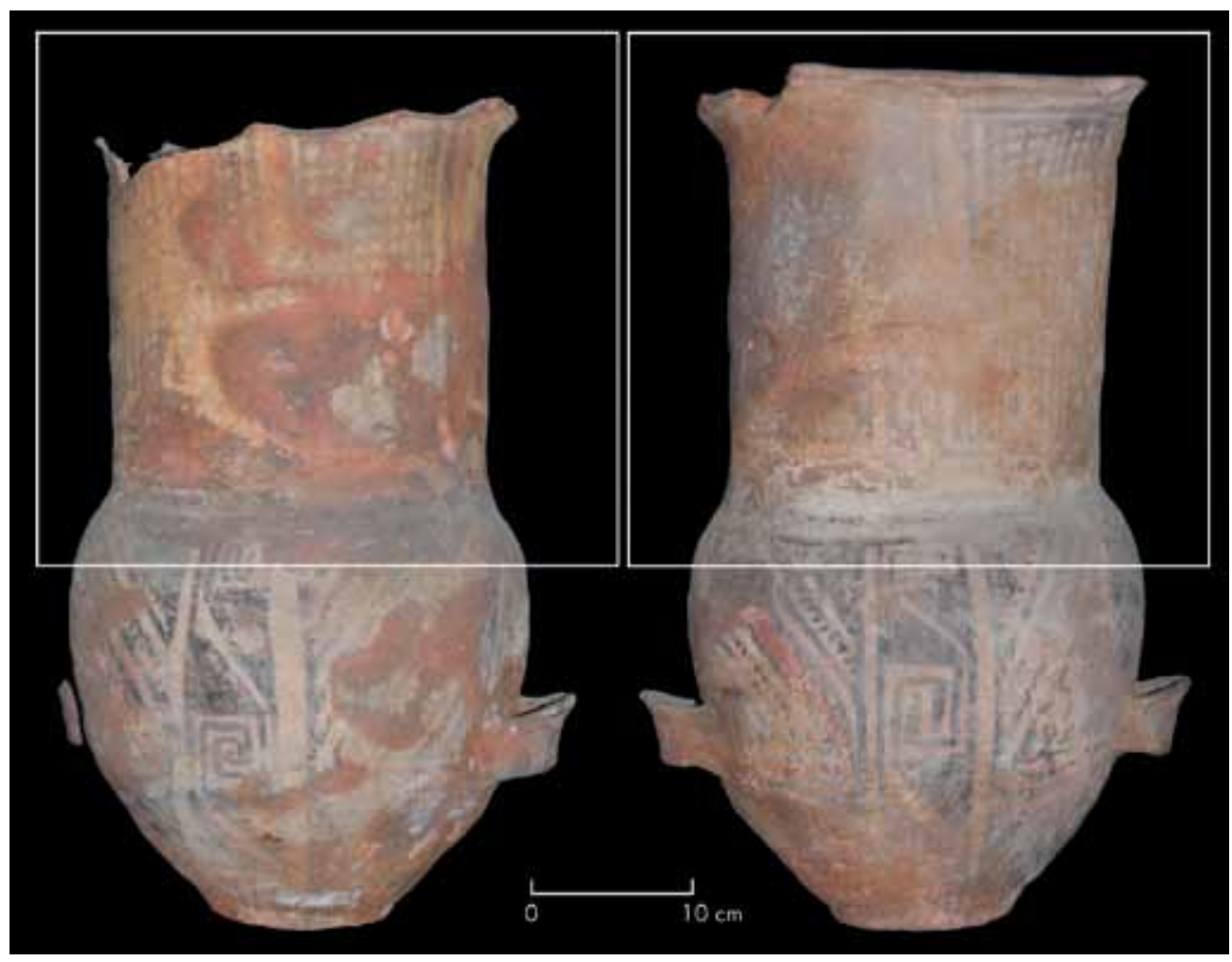

Figura 12. Ejemplo de urna con representación en el cuello de un motivo de ornamento facial. Procedente de Cafayate. MEJBA, número de repositorio: Z-10160.

Figure 12. Example of an urn with facial ornament motif on the neck. From Cafayate. MEJBA, catalogue number: Z-10160. 


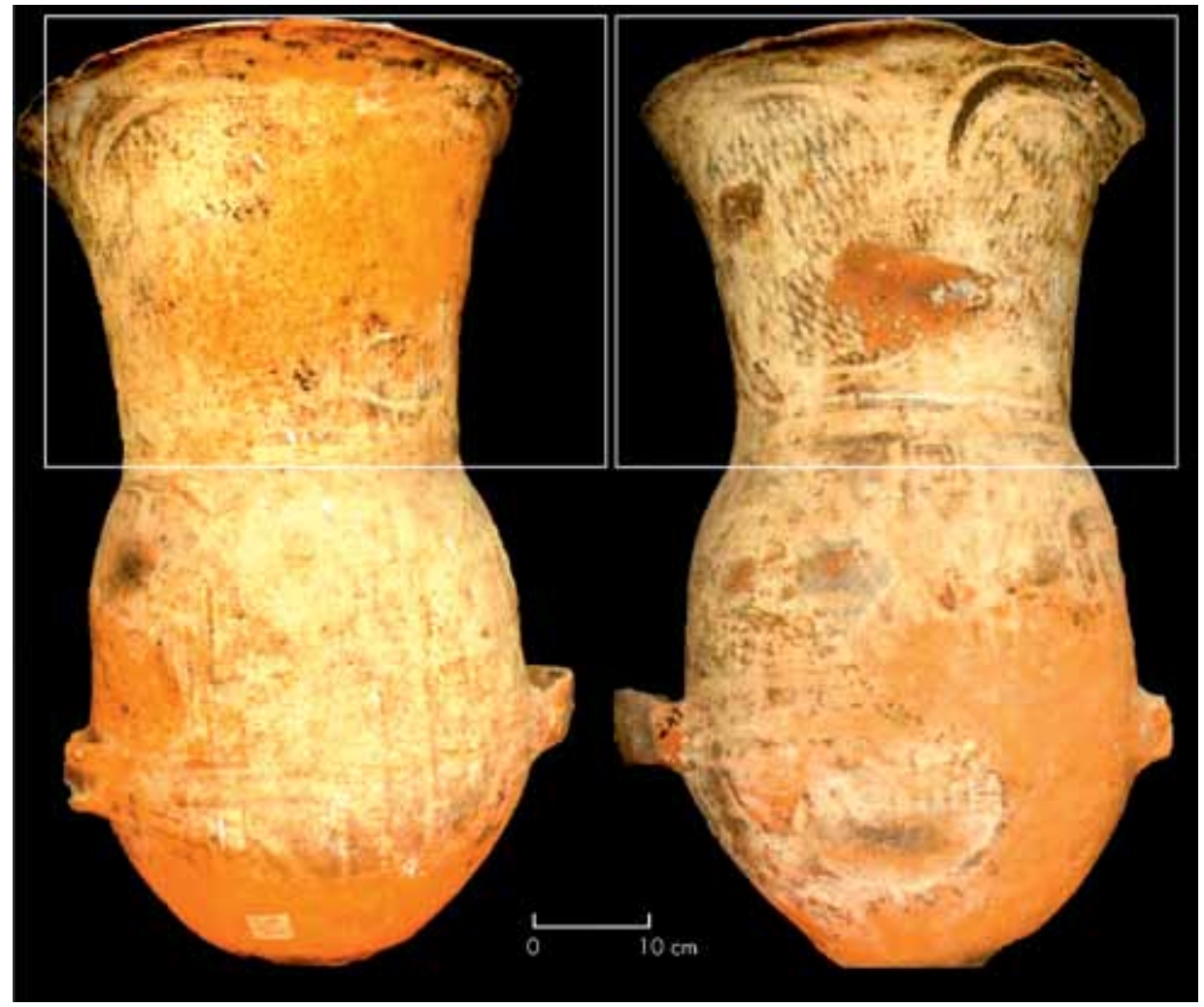

Figura 13. Ejemplo de urna con representación en el cuello de un motivo de ornamento facial. Sin procedencia. Museo Arqueológico Provincial Eric Boman (MAPEB), número de repositorio: 248 o 452/80.

Figure 13. Example of an urn with facial ornament motif on the neck. Unknown origin. Museo Arqueológico Provincial Eric Boman (MAPEB), catalogue number: 248 or 452/80.

esta forma y similar agujero de suspensión, que han sido clasificados como cuchillos (Mayer 1986; Ambrosetti 2011: 45-47). Si bien por cuestiones de peso el bronce no sería un material ideal para llevar colgando de la nariz, debe recordarse que dichos ornamentos también pudieron ser fabricados para ser colocados en los rostros de los muertos, como en el caso de la máscara funeraria Moche ilustrada en la figura $25 .^{3}$

En Moche las narigueras también fueron profusamente representadas en la iconografía junto con las orejeras. Estas son tal vez el adorno facial más mencionado en las crónicas del siglo XVI, existiendo muchos testimonios materiales metálicos preinkaicos (fig. 26). Solo un caso se presta a su reconocimiento en el contexto santamariano, pero en virtud de su excepcionalidad no es posible aseverar su referente con seguridad (fig. 27).

Uno de nosotros ha acuñado la denominación de sobre-rostros para hacer referencia a la representación de rostros de animales por encima de rostros antropomorfos, tales como los de las figuras de las largas cejas (Nastri 2008). Los ojos, y en ocasiones también la nariz y la boca de estos sobre-rostros, son generados a partir de la técnica de pintura negativa, con lo cual se consigue un efecto de resaltamiento del motivo (figs. 28,29 y 30 ). ${ }^{4}$ En virtud de su posición y a partir de la comparación con piezas La Aguada modeladas, en las cuales se hace más explícita la representación, interpretamos tales motivos como atuendos cefálicos confeccionados con la cabeza y la piel de distintos animales: felinos y aves, principalmente (González 1998: 208-209; Nastri 2008). La comparación con imágenes arqueológicas de contextos peruanos (fig. 31) permite plantear que tales atuendos habrían sido atributos de jefes, sacerdotes y guerreros, a la vez que de deidades a imagen de los anteriores (Hocquenghem 2005). Y en una dirección similar apuntan las crónicas del inkario, destacando el uso de los atuendos en cuestión en los ritos de iniciación de los jefes:

Y hecho esto, poníanse unas cabezas de leones fieros y vuelven con gran estruendo a la plaza del Cuzco en donde estaba una gran maroma de oro que la cercaba toda, sosteniéndose en horcones de plata y de oro. En el comedio de esta plaza bailaban y hacían grandísimas fiestas a su modo; y los que han de ser caballeros cubiertos con las cabezas de leones que tengo dicho para dar a entender que serán valientes y fieros como lo son aquellos animales (Cieza de León 1943 [1871]: 63-64, el énfasis es nuestro). 
El que había de ser Inca se vistia un dia de una camisola negra, sin collar, de unas pinturas coloradas, y en la cabeza con una trenza leonada se ha de dar ciertas vueltas, y cubierto con una manta larga leonada ha de salir de su aposento é ir al campo á cojer un hace de paja [...] (Cieza de León 1943 [1871]: 61, el énfasis es nuestro).

Y dicen que por la comarca enviaron mensajeros que [a] todos los que viniesen a querer ser vecinos del Cuzco les serían dadas tierras en el valle y sitio para casas y serían privilegiados, y asi vinieron de muchas partes. Pasado esto, el capitán Inga Yupangue salió a la plaza donde estaba la piedra de la guerra, puesta en su cabeza una piel de león para dar a entender que había de ser fuerte como lo es aquel animal (Cieza de León 1943 [1871]: 220, el énfasis es nuestro)

Refiriéndose a los cultos realizados a lo largo del año, Cristóbal de Molina (1959 [1573]: 77) describe una

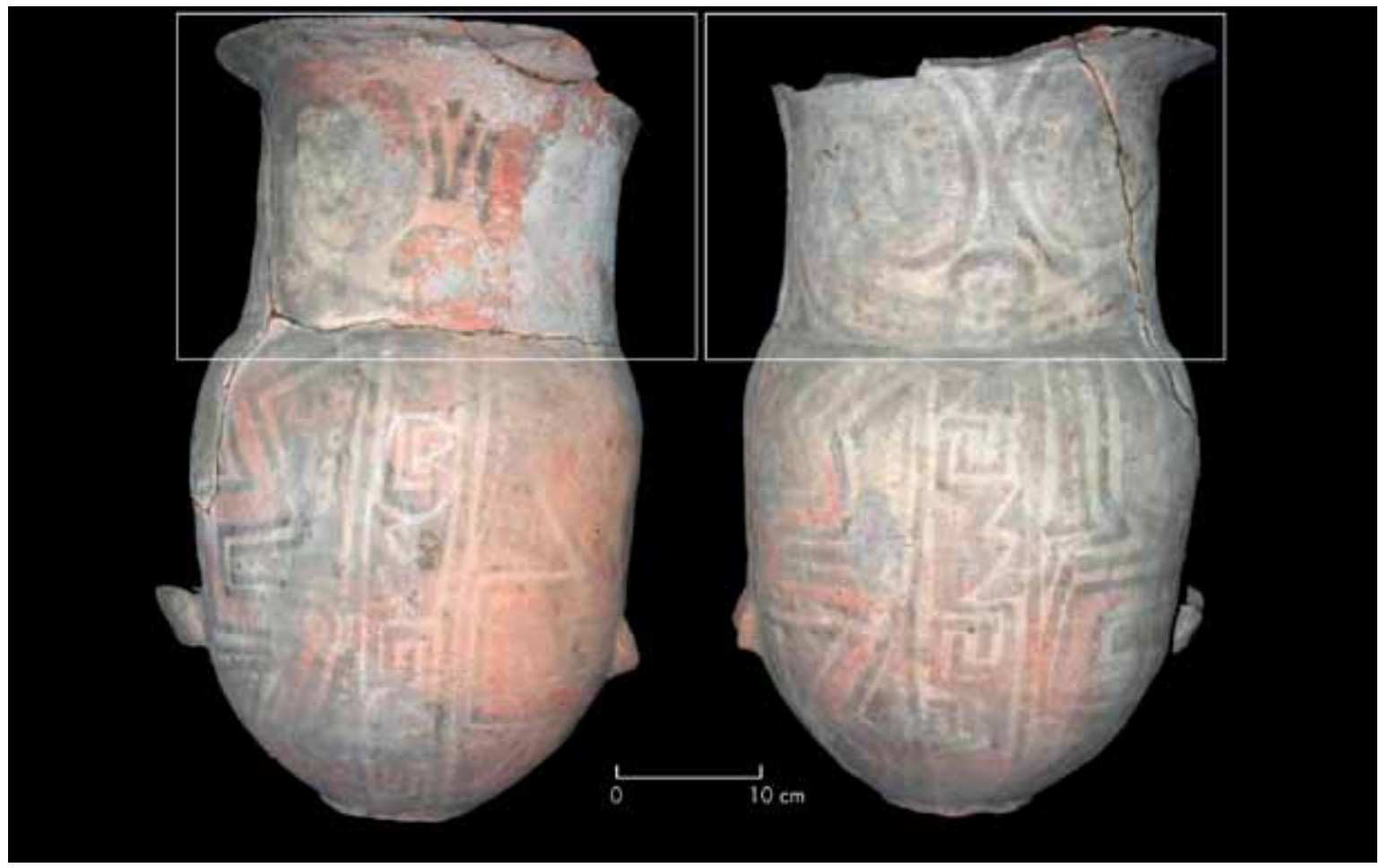

Figura 14. Ejemplo de urna con representación en el cuello de un motivo de ornamento facial: p1061. Procedente de Fuerte Quemado. MEJBA, número de repositorio Z-8468 (colección Zavaleta).

Figure 14. Example of an urn with facial ornament motif on the neck: 1061 . From Fuerte Quemado. MEJBA, catalogue number Z-8468 (Zavaleta Collection)

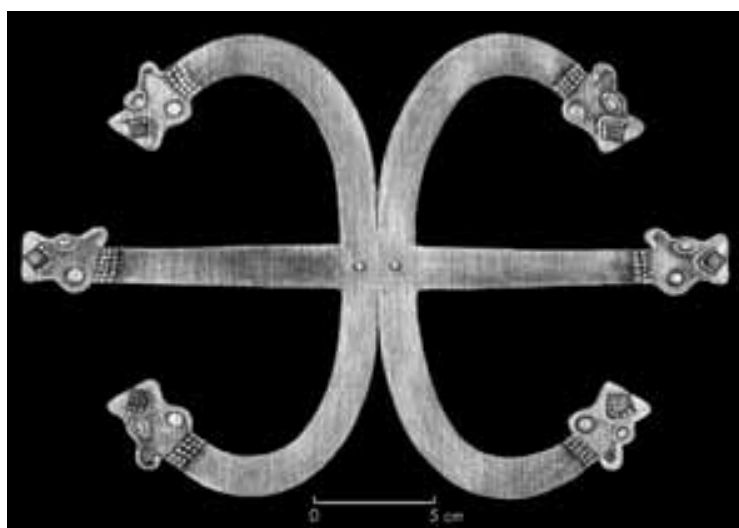

Figura 15. Mascarilla La Aguada procedente de la quebrada de Quixca Utula, provincia de Tucumán (modificado de González 1998: 152). Figure 15. La Aguada Mask from Quixca Utula ravine, Tucumán Province (modified from González 1998: 152).

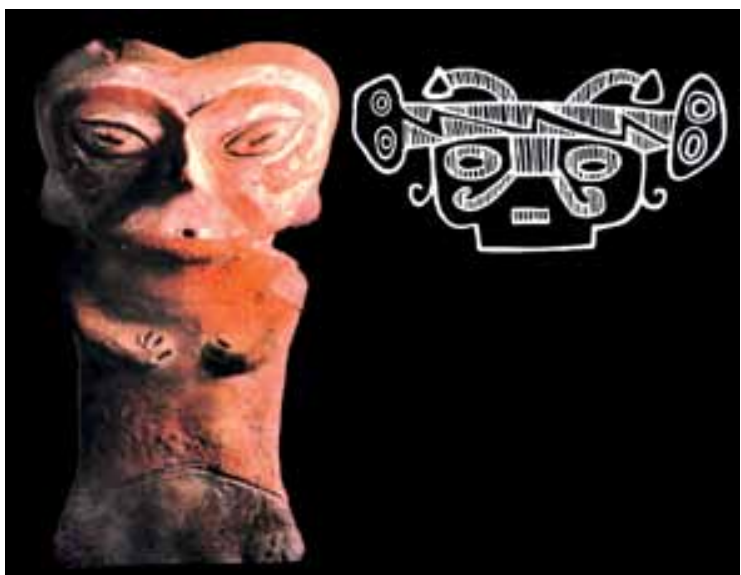

Figura 16. Representaciones de mascarilla en la cerámica La Aguada (modificadas de González 1998: 13,153)

Figure 16. Representation of masks in La Aguada ceramics (modified from Gonzâlez 1998: 13,153). 


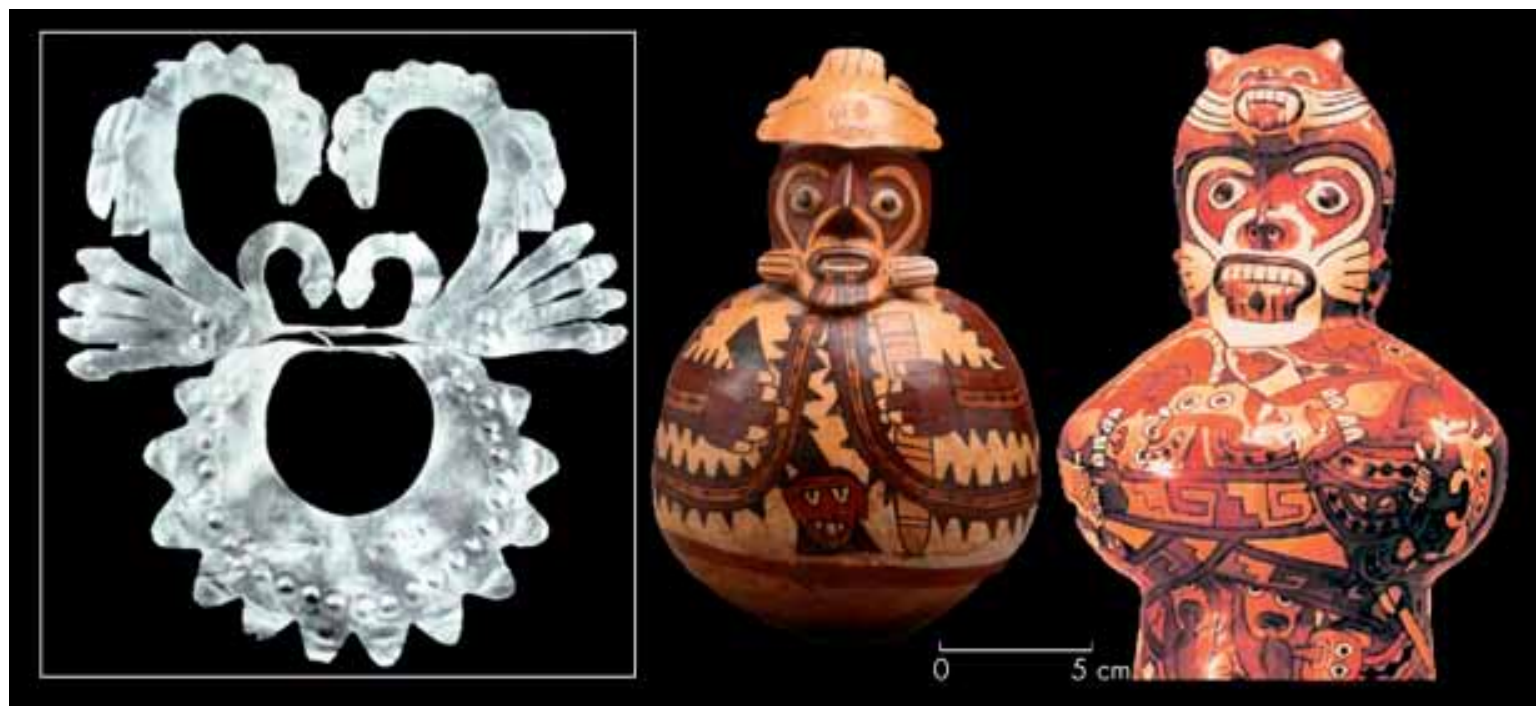

Figura 17. A la izquierda, mascarilla de boca Nasca (Tucshingam 1976: 107); a la derecha, vasija Paracas (Museo de América: <http:// www.mcu.es/novedades/2009/novedades_Textiles_Paracas.html> [consultado: febrero de 2012] y vasija Nasca con representación de una mascarilla de boca y atuendo cefálico (Proulx 2006).

Figure 17. On the left, Nasca mouth mask (Tucshingam 1976: 107); on the right, Paracas vessels (Museo de América: <http://www.mcu. es/novedades/2009/novedades_Textiles_Paracas.html> [accessed:February 2012] and Nasca vessel with representation of a mouth mask and headdress (Proulx 2006).

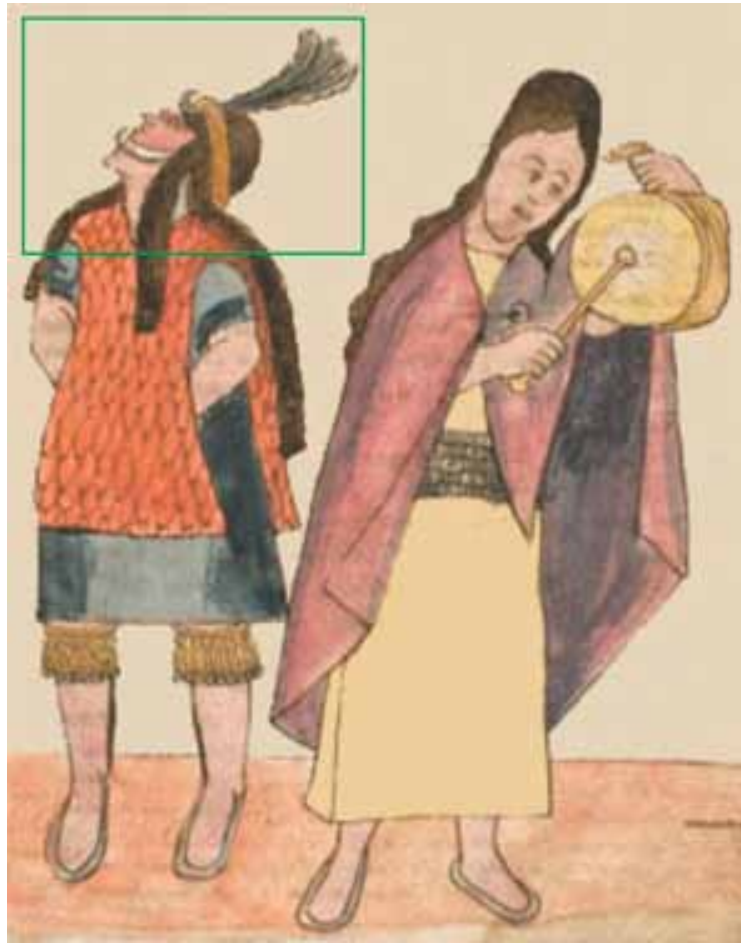

Figura 18. Acuarela de Guamán Poma en la que se representa a "dos músicos del Contisuyu", uno de los cuales exhibe un adorno facial indicado por el recuadro verde (Murúa 2008 [1590]: lámina 4). Figure 18. Watercolor by Guamán Poma depicting "two musicians from Contisuyu," one of whom is wearing a facial ornament (inside the green inset) (Murúa 2008 [1590]: plate 4). fiesta instaurada por Manco Cápac, la cual se llevaba a cabo en noviembre. Concluida la adoración a las huacas y las reverencias a los muertos presentes en la fiesta,

[...] se asentaban todos por sus parcialidades, los de Anancuzco y Hurincuzco, tenían ya aparejados unos leones desollados, y las cabezas vacías teníanlas puestas, y en las orejas unas orejeras de oro, y en las cabezas unas patenas de oro, y en lugar de los dientes, que los habían sacado, les ponían dientes de oro, y en las manos unas ajorcas de oro que llaman chipana. Llamaban a estos leones huillca cunga chuqui cunga; poniéndoselos en las cabezas de suerte que todo el pescuezo y cabeza sobrepujaba sobre el que se vestía, y el cuerpo del león le quedaba en las espaldas (el énfasis es nuestro).

De los sobre-rostros registrados hasta el momento en el arte santamariano son minoritarios los casos en que los referentes de los mismos son felinos; las aves parecen tener preeminencia. Si el puma es sinónimo de fuerza, las aves lo son de vuelo y de visión. El mencionado caso del vaso modelado La Aguada que constituye el ejemplo más elocuente (Nastri 2008) corresponde a un murciélago, otro animal muy admirado en los Andes:

Al ave que ellos llaman Cúnturpor su grandeza, y a las águilas adoraban ciertas naciones porque se precian descender de ellas y también del Cúntur. Otras naciones adoraban los halcones, por su ligereza y buena industria de haber por sus manos lo que han de comer; adoraban al búbo por la hermosura de sus ojos y cabeza, y al murciélago por la sutileza de su vista, que les causaba mucha admiración que viese de noche. Y otras muchas aves adoraban como se les antojaba. A las culebras grandes por su monstruosidad y fiereza (Garcilaso de la Vega 1941-1943 [1609]: capítulo IX, el énfasis es nuestro). 


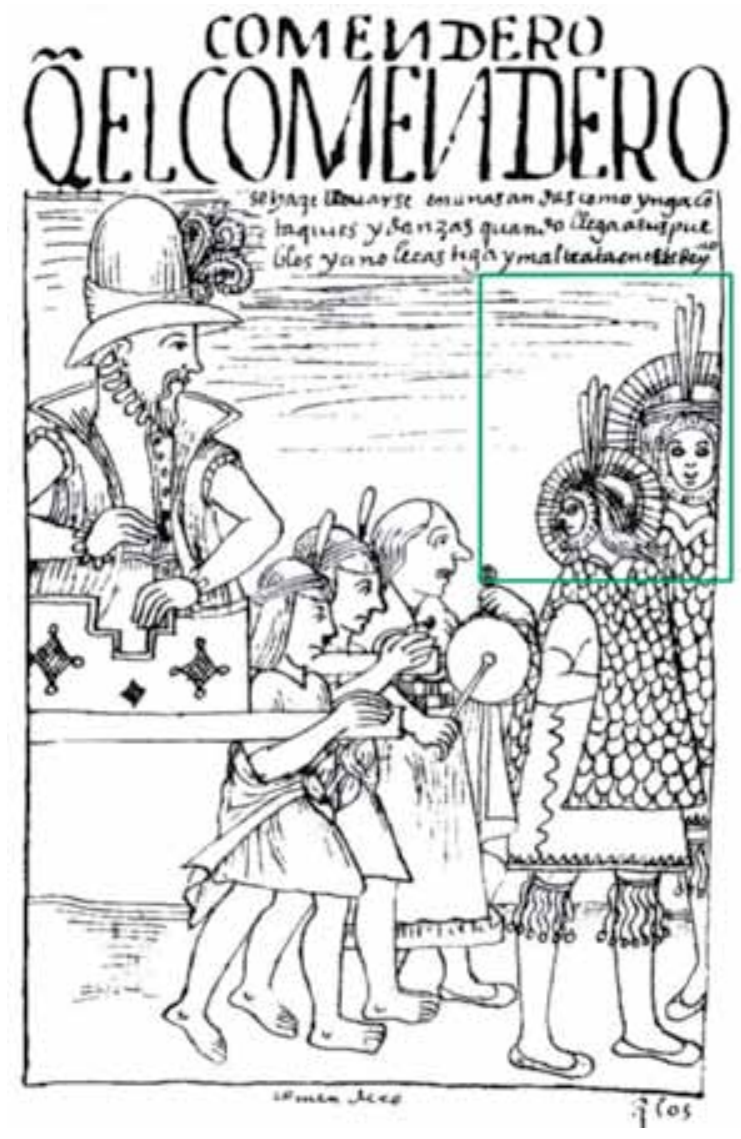

Figura 19. Grabado que representa a un encomendero y a dos jefes indígenas con adornos faciales indicados por recuadro verde (Guamán Poma 1988 [1615]: 568).

Figure 19. Engraving depicting an "encomendero" (Spanish feudal lord) and two indigenous chiefs with facial ornaments in the green inset (Guamán Poma 1988 [1615]: 568).

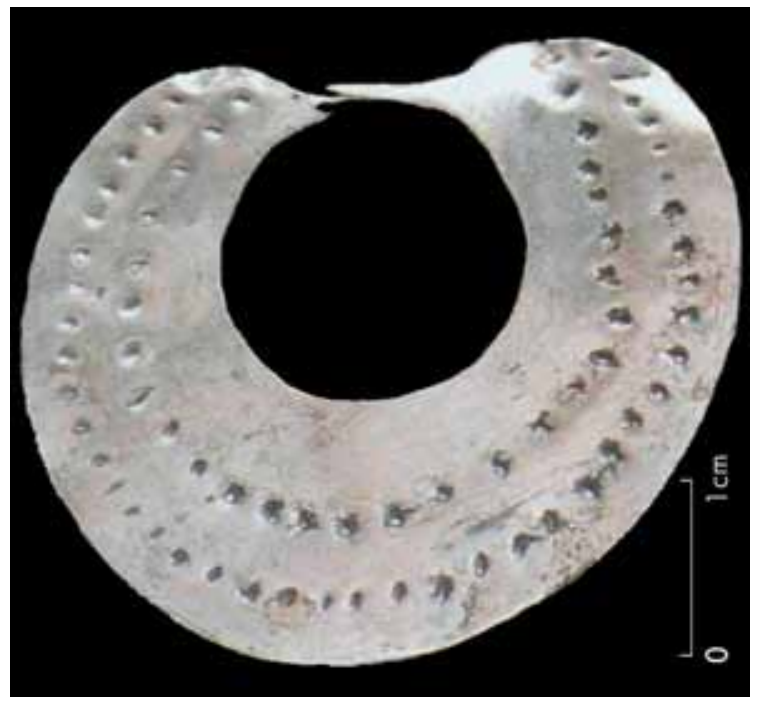

Figura 20. Nariguera de plata circular Moche (presenta sencilla decoración de puntos) (Schindler 2000: 94).

Figure 20. Moche circular silver nose ornament (with simple indentation decoration) (Schindler 2000: 94).

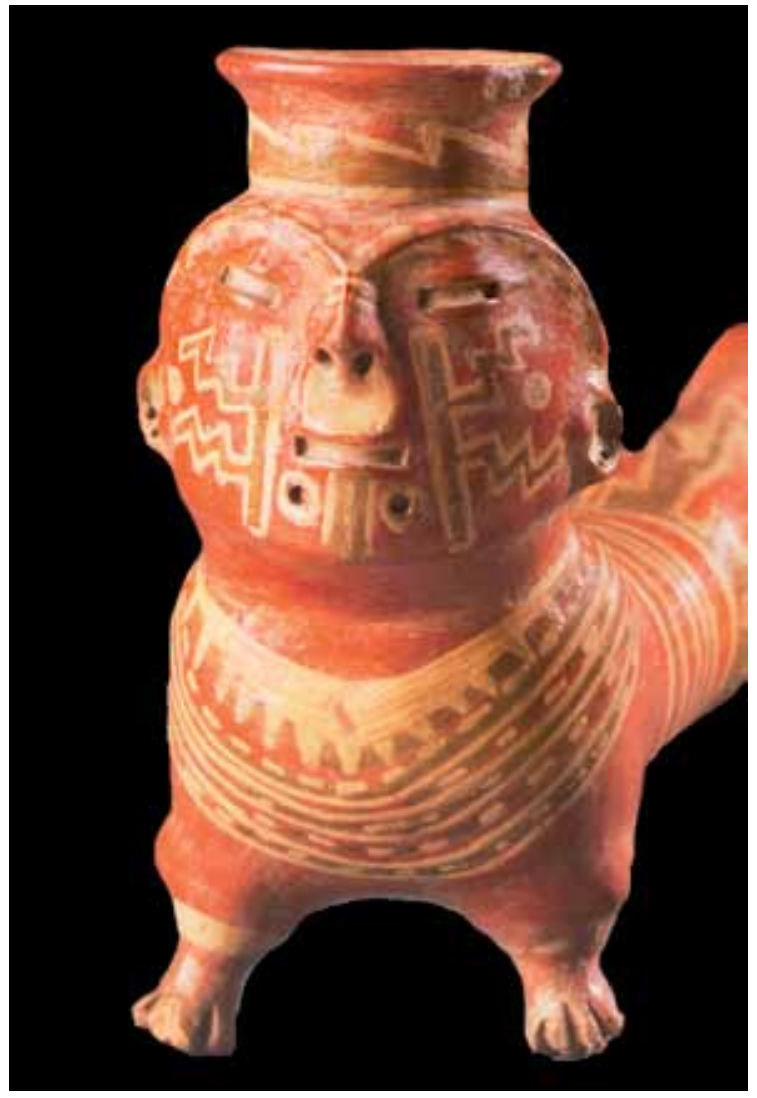

Figura 21. Pieza Condorhuasi representando un personaje con nariguera (tomado de Goretti 2006: 235). Procedente de Las Faldas (Departamento de Belén). Largo: $28 \mathrm{~cm}$.

Figure 21. Condorbuasi piece representing a figure with nose ornament (from Goretti 2006: 235). From Las Faldas (Belén Department). Length: $28 \mathrm{~cm}$.

Es interesante señalar que muchos de los casos de sobre-rostros cuentan también con un motivo rojo dispuesto sobre los ojos, a los costados de la nariz y por debajo de la boca que, probablemente, haya sido también un adorno facial (Nastri 2008: 16-17).

\section{LO MISMO, LO OTRO Y LO ANÁLOGO}

La comparación con especímenes materiales de adornos faciales y de su representación en la iconografía de los Andes centrales y del NOA, nos permite afirmar que lo representado en las mejillas de las urnas no habrían sido ni ornamentos sin significación o referente real, tampoco siempre directamente alteraciones analogistas de los referentes reales, sino en muchos casos ornamentos que en sus versiones originales fueron diseñados empleando este procedimiento.

La comparación entre dos contextos históricos distintos pone al investigador ante el desafío de articular 


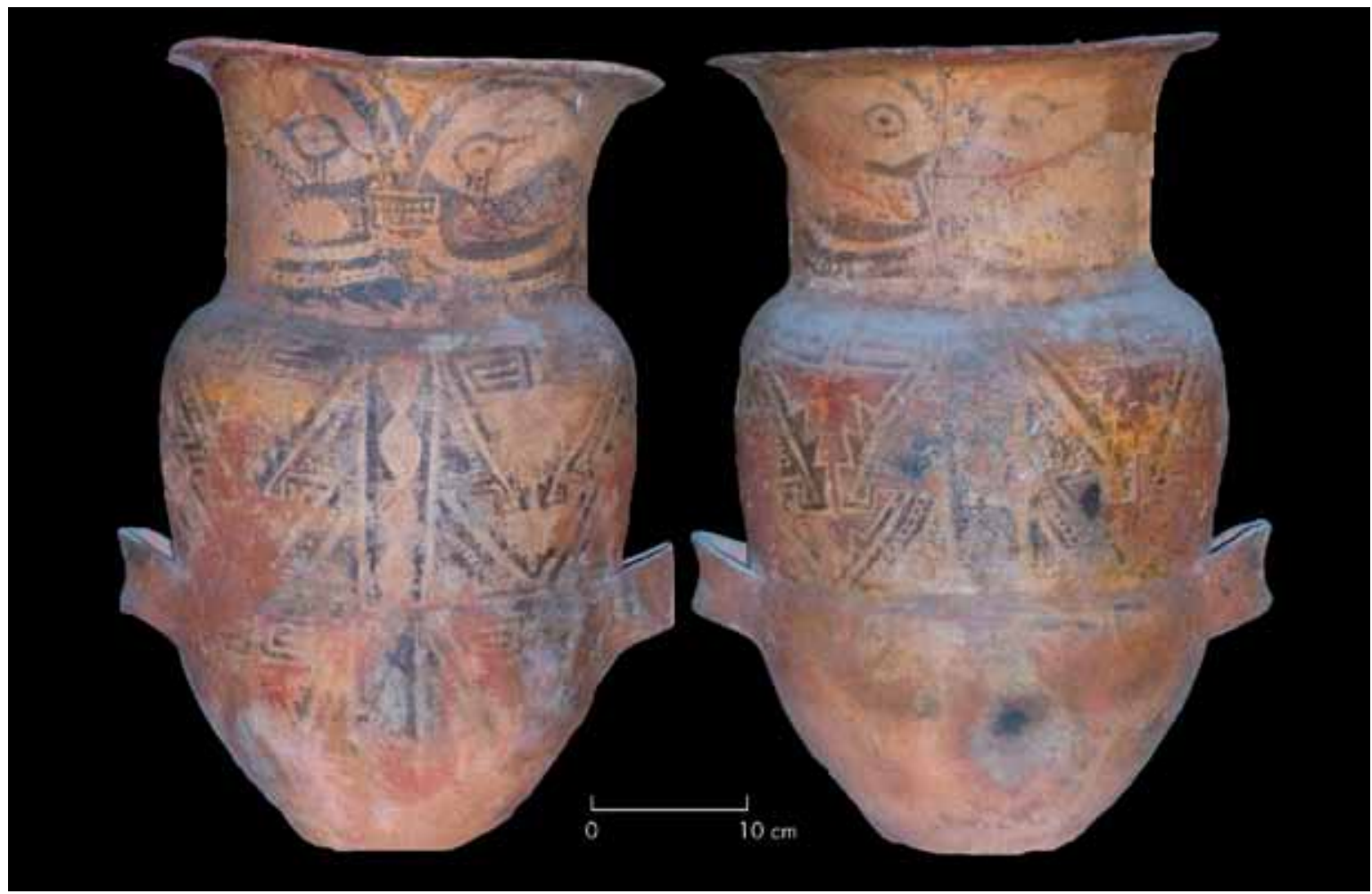

Figura 22. Nariguera transversal en pieza procedente de Ayuza, Alemanía. Museo Antropológico de Salta Juan Martín Leguizamón, número de repositorio 834.

Figure 22. Horizontal nose ornament on a vessel from Ayuza, Germany. Museo Antropológico de Salta Juan Martín Leguizamón, catalogue number 834 .

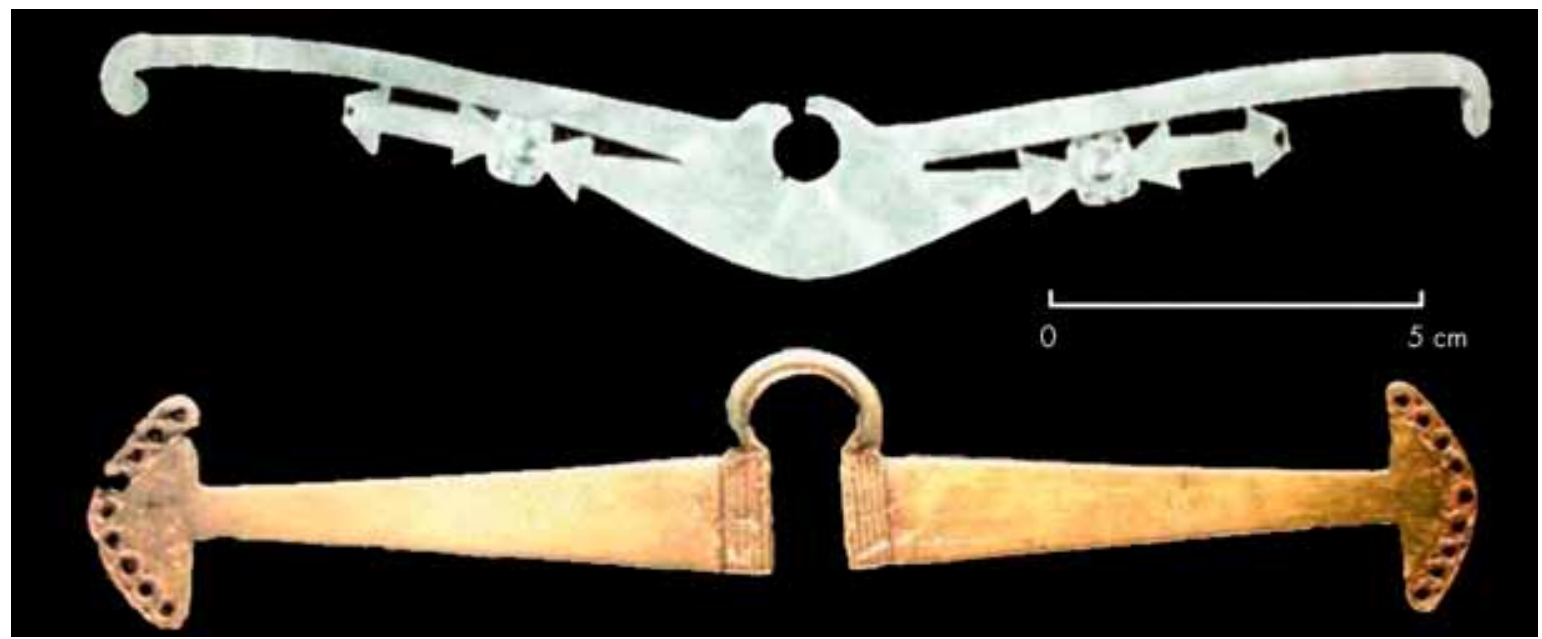

Figura 23. Narigueras transversales peruanas (Pérez de Barradas 1954: lámina 172 y Schindler 2000: 93)

Figure 23. Horizontal nose ornaments from Peru (Pérez de Barradas 1954: plate 172 and Schindler 2000: 93).

los modelos de lo Mismo, lo Otro y lo Análogo en la construcción histórica. El modelo de lo Mismo implica una cierta yuxtaposición temporal, en la medida en que se basa en una reefectuación del pasado (Ricoeur 1995: 840). A partir de reportes de los cronistas, o de los diferentes contextos arqueológicos andinos conocidos, podemos revivir la vigencia de ornamentos faciales en la sociedad calchaquí, con una gran densidad de significaciones. Pero a esto se enfrenta la crítica historiográfica del modelo de lo Otro, el cual postula la 


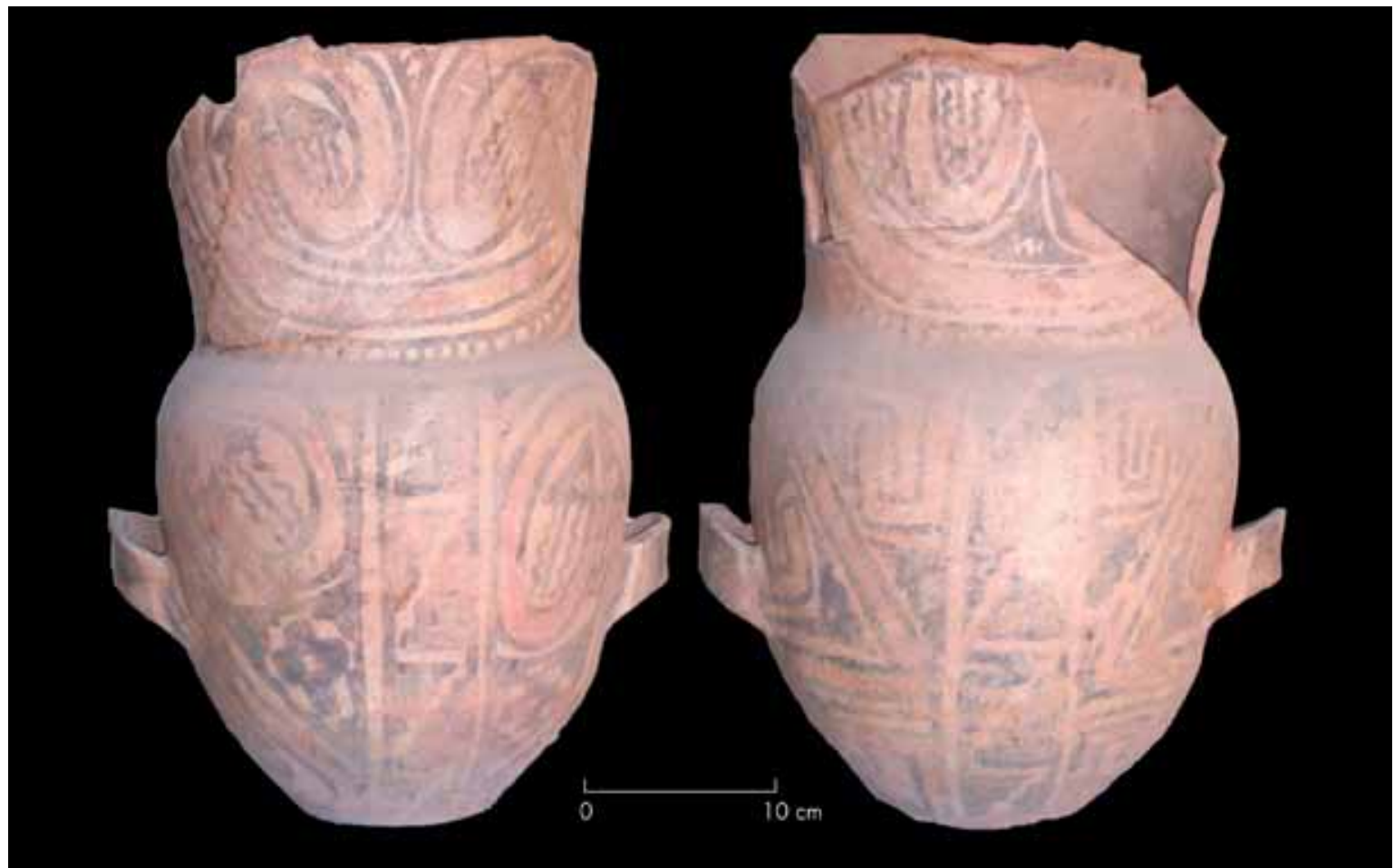

Figura 24. Nariguera semilunar en pieza sin procedencia. MASML, número de repositorio 16-101-82. Figure 24. Half-moon nose ornament on a piece of unknown origin. MASML, catalogue number 16-101-82.

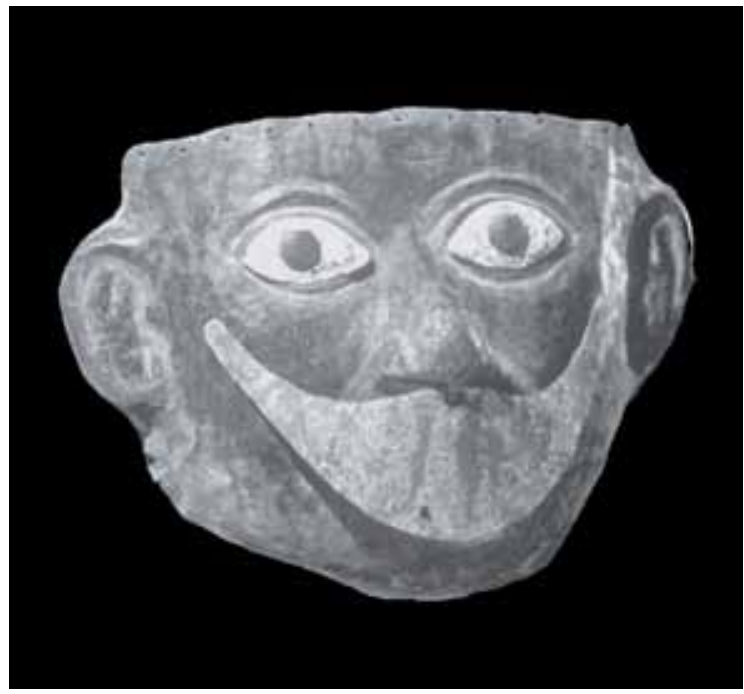

Figura 25. Nariguera semilunar peruana (Donnan 2008: 72). Figure 25. Half-moon nose ornament from Peru (Donnan 2008: 72).

alteridad radical del pasado y combate todo intento de proyección de análogos u otras ideas, como violencia interpretativa. Aquí cabe destacar la existencia de formas que no tienen un correlato exacto con ejemplos arqueológicos o iconográficos conocidos, lo cual pone

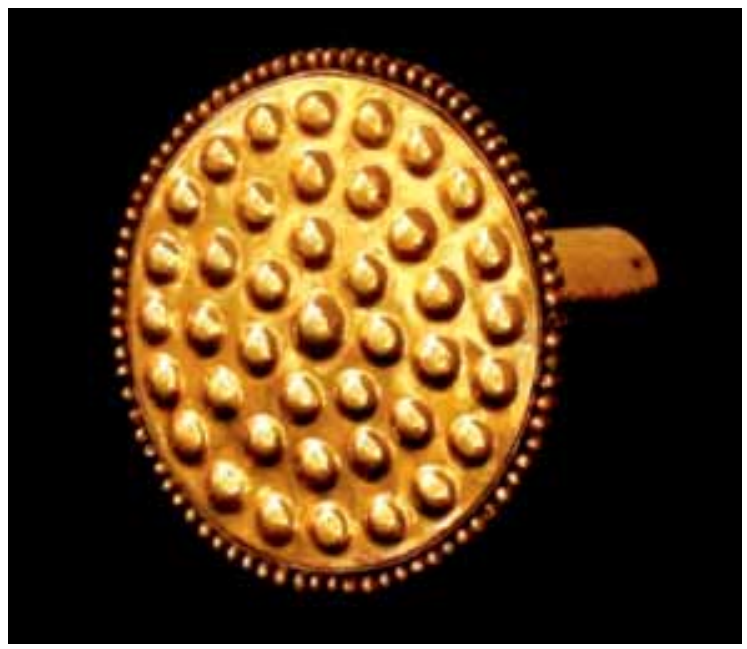

Figura 26. Orejera peruana de aleación de oro con círculos embutidos. Estilo Lambayeque o Sicán. Museo Nacional de Antropología, Arqueología e Historia del Perú (MNAAHP).

Figure 26. Peruvian ear ornament of gold alloy with embossed circles. Lambayeque or Sicán style. Museo Nacional de Antropología, Arqueología e Historia del Perú (MNAAHP).

en duda su asignación y, por consiguiente, también las interpretaciones más generales que pueden desprenderse, por ejemplo, acerca de los motivos en cuestión como símbolos de poder. Finalmente, el modelo de lo Análogo constituye una conjugación de los dos anteriores -el 


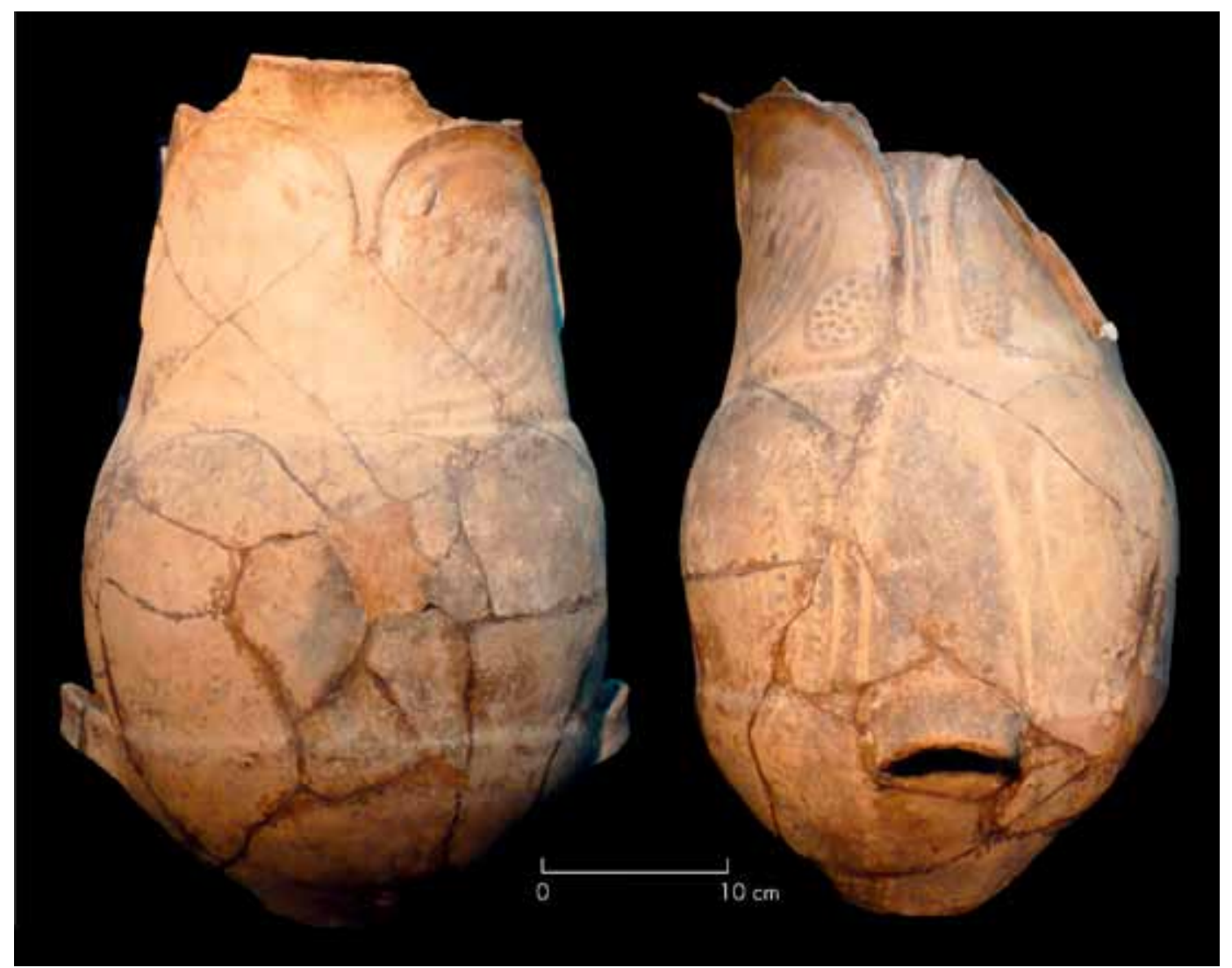

Figura 27. Representación de orejera en urna santamariana procedente de Pampa Grande (Salta). MEJBA, número de repositorio: 28193. Figure 27. Representation of ear ornament on a Santa Maria urn from Pampa Grande (Salta). MEJBA, catalogue number: 28193.

de lo Mismo y el de lo Otro- que Ricoeur (1995: 839) rescató de la obra de Platón. La analogía alude a la semejanza entre relaciones, antes que entre términos simples. El modelo de lo Análogo no reemplaza a los anteriores, sino que los complementa. De manera que, a partir de la comprensión de la utilización de adornos con determinados materiales, formas y dispositivos de sujeción, es posible imaginar variantes posibles y entender elementos desconocidos en términos de los anteriores. Similitud, diferencia y analogía resultan entonces factores cruciales tanto para relacionarse con el mundo por parte de las poblaciones del pasado -tal como se plantea en el esquema de Descola-, como para conocer dicho pasado a partir de la investigación arqueológica. No existe una fórmula o receta acerca de la medida en que la reefectuación del pasado, el descubrimiento de la alteridad y la analogía entre términos relacionados en distintos contextos se articulan para la generación de la representación del pasado más ajustado a la realidad histórica. Es la coherencia del panorama resultante, su correspondencia con el mayor número de datos y la generación de implicancias que puedan ser puestas a prueba con nuevos hallazgos (tanto en el campo como en los depósitos de los museos), lo que permitirá alcanzar interpretaciones cada vez más completas y convincentes.

La similitud entre los objetos arqueológicos de contextos precolombinos tales como La Aguada, Nasca, Moche, Vicús y Chimú (Pérez de Barradas 1954; González 1974, 1998; Schorsh et al. 1996; Donnan 2008) y las representaciones pintadas de atributos de la figura de las largas cejas de la iconografía santamariana, indican que dichos símbolos de poder y de estatus eran al menos conocidos por la sociedad calchaquí. En una porción minoritaria de las piezas que integran el corpus $(14 \%)$, la figura de las largas cejas presenta atributos de estatus como mascarillas faciales o bucales, narigueras y sobre-rostros. En la identificación, optamos por ser cautelosos y consignar solo los casos en los que se pudieran reconocer formas similares a objetos reales conocidos. Pero aun empleando criterios más laxos, difícilmente el porcentaje superaría el $20 \%$ de la muestra. Esta fracción es, no obstante, en números absolutos, lo suficientemente amplia como para indicar que en todas 


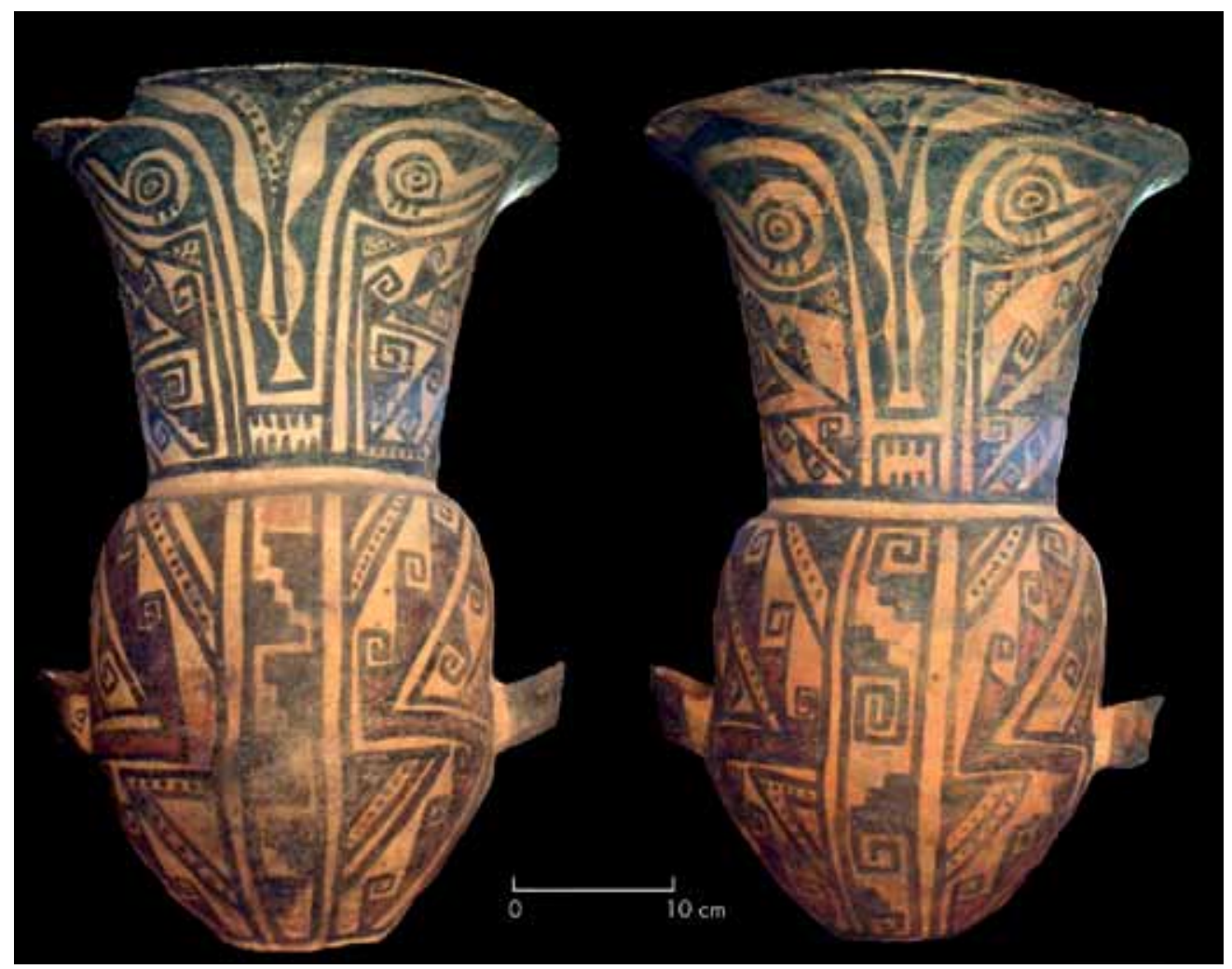

Figura 28. Ejemplo de sobre-rostro en urna sin procedencia. MAPEB, número de repositorio: 262 o 56/75a o 20/91. Figure 28. Example of a "sobre-rostro" on an urn of unknown origin. MAPEB, catalogue number: 262 or 56/75a or 20/91

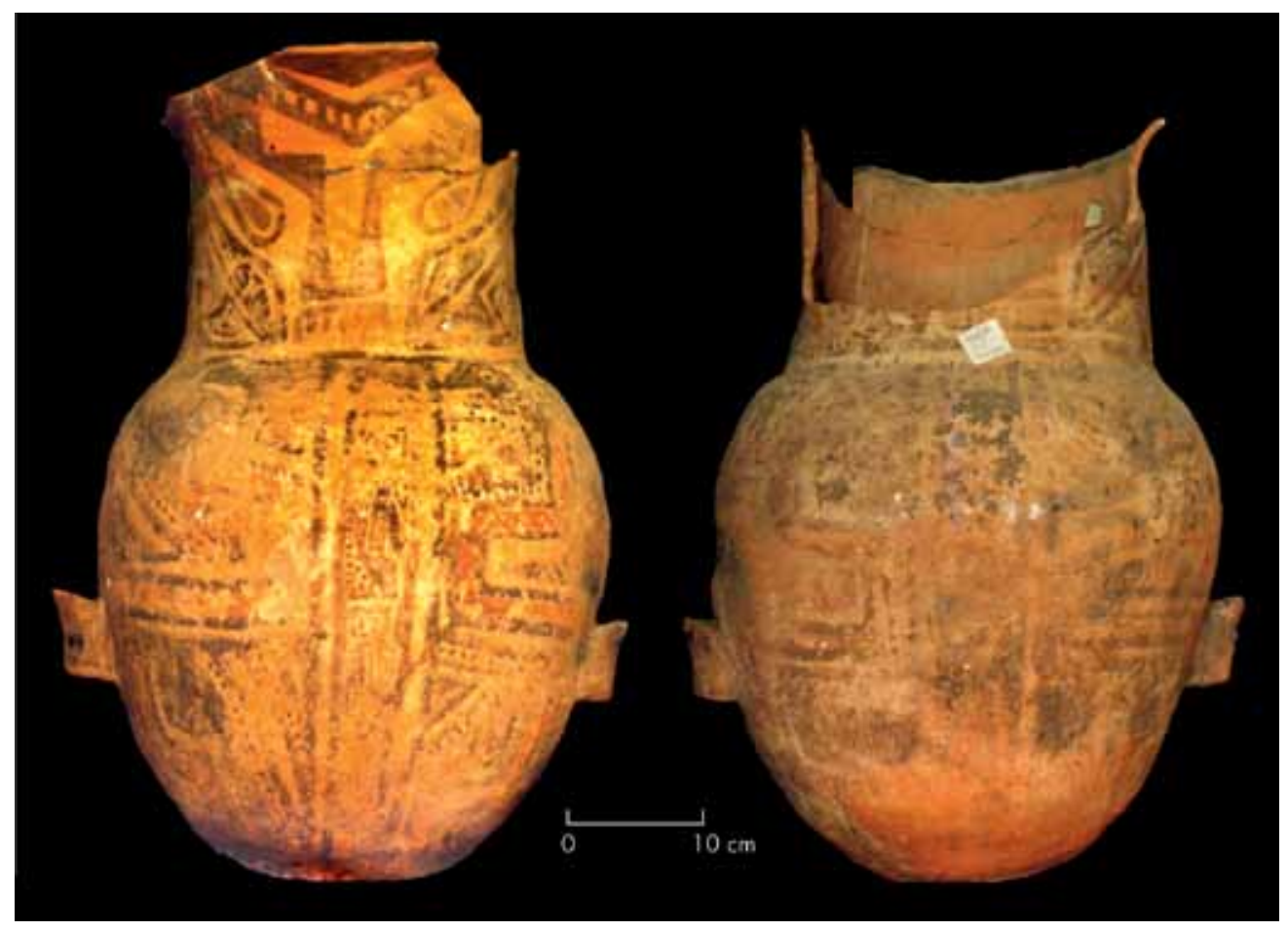

Figura 29. Ejemplo de sobre-rostro en urna sin procedencia. MAPEB, número de repositorio: 6CB o 11/91 CB. Figure 29. Example of "sobre-rostro" on an urn of unknown origin. MAPEB, catalogue number: 6CB or 11/91 CB. 


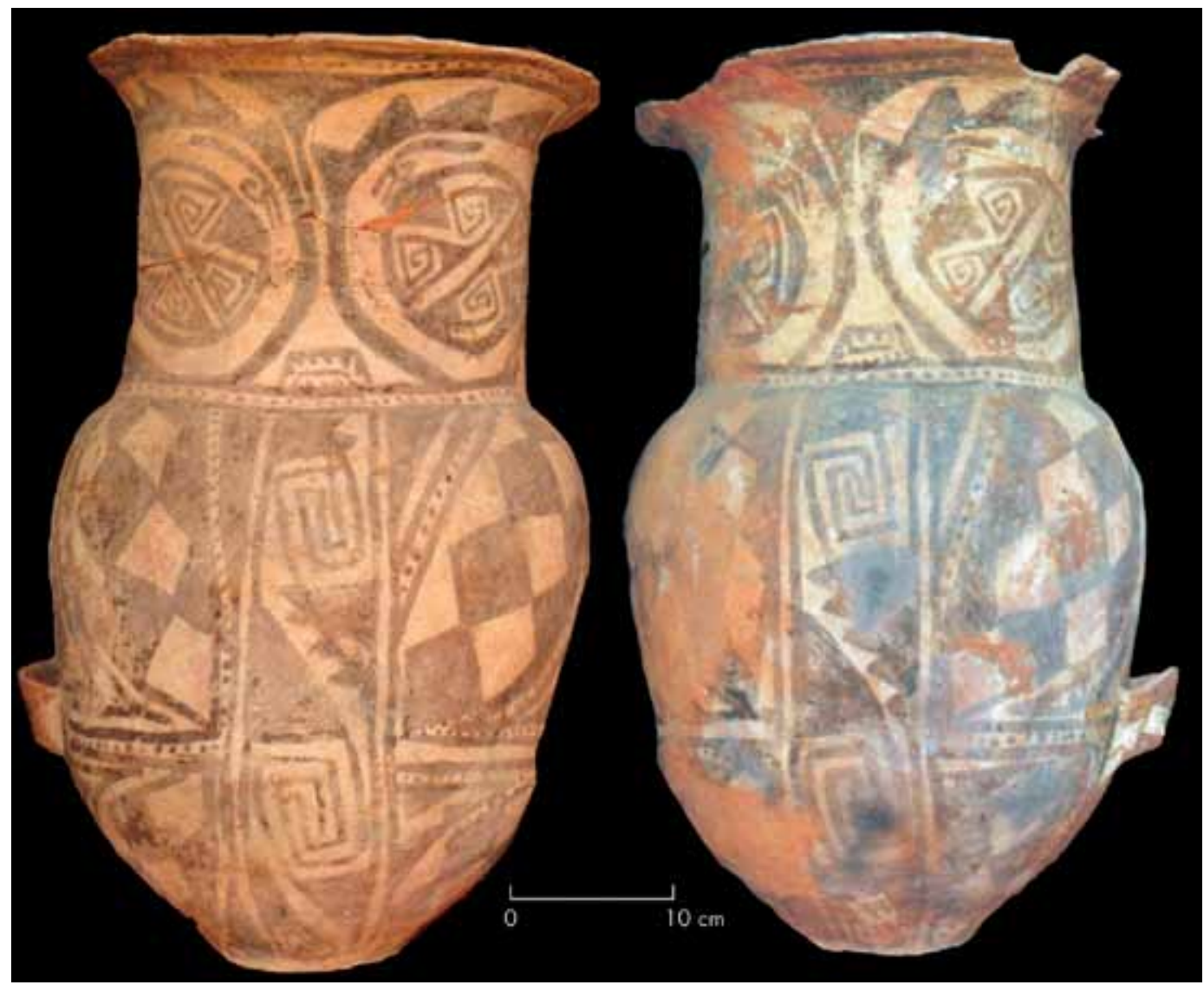

Figura 30. Ejemplo de sobre-rostro en pieza sin procedencia. MAPEB, número de repositorio: $256 \mathrm{CB}$. Figure 30. Example of "sobre-rostro" on a piece of unknown origin. MAPEB, catalogue number: 256 CB.

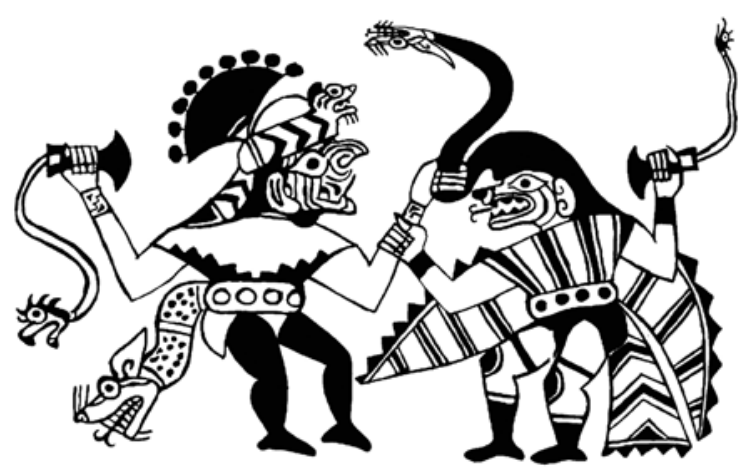

Figura 31. Decoración pintada de escena de combate ritual en un ceramio moche (Donnan et al. 2008: 118).

Figure 31. Painted scene of ritual combat on a Moche ceramic vessel (Donnan et al. 2008: 118).

las áreas correspondientes a la distribución de las subtradiciones santamarianas (Nastri 2008) se conocían los objetos de adorno, que en sociedades andinas previas y contemporáneas a los calchaquíes fueron usadas en forma distintiva por nobles, gobernantes, sacerdotes u oficiantes de rituales.
Un desafío pendiente es articular los motivos representativos naturalistas con los abstracto-geométricos, como el caso de la no coexistencia en una misma pieza de representaciones de ornamentos y de particiones simbólicas. La determinación de las copresencias o la incompatibilidad de presencia de distintos referentes en una misma pieza constituyen pistas sumamente relevantes respecto del papel de ciertos símbolos en el orden social calchaquí. En este sentido resulta urgente ampliar el conocimiento del papel de las urnas en la vida cotidiana. Trabajos en curso muestran su participación aún fragmentada como contenedores en los pisos de ocupación de distintas clases de instalaciones (Nastri et al. 2011). Tal conocimiento permitirá comprender mejor qué representa la figura de las largas cejas: ¿al párvulo contenido en las urnas, investido en ocasiones con símbolos de estatus? ¿A personajes sociales no individualizados de la sociedad calchaquî? ¿A ancestros individualizados a quienes se tenía materialmente presentes en la vida cotidiana mediante su representación en la figura de las largas cejas hasta que, ante la muerte de un niño, las urnas pasaban a constituir su contenedor y eran depositadas en los cementerios? 
Vinculado con lo anterior, resta considerar los cambios experimentados por el género discursivo de las urnas, cuestión que requiere una base cronológica más amplia que la existente hoy. Por el momento puede decirse que los ornamentos identificados desaparecen hacia el final de la secuencia, cuando adquieren protagonismo motivos asociados a prácticas violentas, como la guerra y el sacrificio.

Finalmente, un tema importante es el de la evaluación de la relación entre representaciones y prácticas, a fin de determinar en qué medida las representaciones fueron una expresión de la realidad o fueron un instrumento ya sea para cambiar su curso, o para ocultarla. Si bien ambas alternativas no son excluyentes, recordar, de acuerdo con Geertz (1992: 122-123), que el carácter del arte es principalmente semiótico, antes que instrumental. Esto quiere decir que el hecho de que una práctica no se represente plásticamente en un momento dado no quiere decir que la misma no haya estado vigente. Mientras que cuando sí es representada, resulta difícil sostener un total desconocimiento de dicha práctica por parte de los agentes del pasado. De esta manera, el conocimiento de los ornamentos faciales y cefálicos por parte de los productores y los usuarios de urnas santamarianas se revela como un dato relevante en torno al debate contemporáneo acerca de la organización política de las sociedades calchaquíes durante el Período Intermedio Tardío. Contra la visión tradicional que asumía una organización de señorío para las formaciones sociales del período en el NOA (Núñez Regueiro 1974; Raffino 1988; Sempé 1999; Tarragó 2000), se han levantado voces que cuestionan el carácter individualista y centralizador del poder (Nielsen 2006, 2007) y otras que directamente rechazan la existencia de desigualdad social, planteando un panorama regido por la "integración comunal" (Acuto 2007).

Nosotros pensamos que las posturas que asumen una única forma de organización política (sea esta más o menos compleja) para toda la región del NOA, para todo el Período Intermedio Tardío, continúan respondiendo a la concepción evolucionista cultural sobre los "niveles de complejidad", más allá de sus críticas a la misma. Coincidimos con Nelson (1995) en que en lugar de preocuparnos por si la sociedad estudiada era más o menos compleja que otras, resulta más interesante interrogarse acerca del "cómo" de su complejidad. Y como punto de partida preferimos la hipótesis de existencia en el pasado de una variedad de formas contemporáneas de organización política a lo largo de tan dilatado territorio, en el seno de las cuales no habrían faltado las tensiones que llevaban a la alternancia de situaciones políticas variables, incluso opuestas, a lo largo del tiempo. Tal como mostrara sugestivamente Isbell (1997) en relación con el fenómeno de las chullpas, es necesario historizar las instituciones andinas -incluso las supuestamente más ancestrales-, así como también no subestimar la importancia en el pasado de otros fenómenos -tales como la violencia y el sacrificio- hoy menos visibles en función de haber sido largamente reprimidos por la Iglesia y los dominios colonial y republicano (Arnold \& Yapita 2006; Arnold \& Hastorf 2008).

Luego de largas décadas de afianzamiento de la arqueología de los contextos culturales tras los excesos difusionistas de la primera mitad del siglo xx (González 1991-1992), es posible hoy nutrirse de la evidencia de contextos culturalmente relacionados como los andinos, a fin de trascender los límites de los modelos individuales de lo Mismo, lo Otro y lo Análogo, hacia el logro de una construcción histórica cabal, capaz de ser significada y puesta a prueba con los hallazgos producidos por las investigaciones de campo en curso.

\section{CONCLUSIONES}

La experiencia de investigación desarrollada nos enseña que a partir del despliegue de un método comparativo sobre muestras extensas, centrado en el seguimiento de las variantes de motivos, es posible acercarnos a la identificación de referentes que tienen importantes implicancias respecto de la cuestión de la organización social de las poblaciones del pasado. La consideración del corpus de investigación, en términos de género discursivo, abre la puerta para la comparación de la serie de productos culturales agrupados por el mismo, como unidades permutables dentro de un continuum de expresión de un discurso o narrativa. El seguimiento de las variantes de los motivos en términos de alteraciones permite superar la masa abigarrada de formas insignificantes o caprichosas e incluso la multiplicación casi infinita de analogías intencionales, tan extendidas en el ámbito andino, hacia la identificación de un mayor número de referentes más directamente vinculados con las prácticas sociales reales, aparte de con las imaginarias. Estos referentes contribuyen a la conformación de una base de conocimiento que, por identificación y analogía con otros contextos arqueológicos mejor conocidos, ayuda en la interpretación de aquellos elementos completamente desconocidos, sobre los que existe lógicamente mayor margen para el error. Partiendo de lo conocido, es posible orientar mejor la búsqueda de lo desconocido, reduciendo el enorme abanico de posibilidades en toda producción de carácter ideosincrático, como es la iconografía cerámica de las poblaciones agroalfareras surandinas. 


\section{NOTAS}

${ }^{1}$ La preservación fragmentada de las urnas funerarias santamarianas en los sitios de habitación del valle homónimo ha impedido, hasta el momento, la reconstrucción de sus contextos de uso en la vida cotidiana. No obstante, esta situación está siendo superada en relación con los recientes avances en las investigaciones en la Sierra del Cajón, tanto en lo que respecta a las urnas santamarianas (Nastri et al. 2011), como a las urnas Belén (Nastri et al. 2010: 1163n6). En cuanto a los hallazgos de urnas en los cementerios, también son recientes los casos de documentación detallada de la disposición y las condiciones de hallazgos de las piezas. Cabe destacar el entierro de un párvulo en urna en el marco de una estructura ceremonial circular en Pichao (Tartusi \& Núñez Regueiro 1993) y de numerosos casos de párvulos en urnas en los cementerios de Rincón Chico (Marchegiani 2008).

${ }^{2}$ La reconstrucción de los contextos excede los límites del presente trabajo.

${ }^{3}$ En este sentido, resulta significativo que el adorno de plumas de oro hallado por Ambrosetti en La Paya tenga su contraparte en una pieza idéntica confeccionada en bronce y procedente de Santa María (Ambrosetti 2011: 82-83); a la vez que existe la versión en cobre de los artefactos semilunares con perforación central superior (como la de las narigueras peruanas), en el caso de una pieza obtenida por Max Uhle en Tilcara (Ambrosetti 2011: 45-46). Es necesario un nuevo análisis del conjunto de estos objetos que tenga como término de comparación los adornos faciales andinos.

${ }^{4} \mathrm{O}$ de ocultamiento, cuando los espectadores no están acostumbrados a reconocer las figuras ejecutadas con esa técnica. Así fue que el mencionado motivo pasó desapercibido a todos los investigadores que se ocuparon del tema, a pesar de estar presente en una importante cantidad de piezas

5 En la gran mayoría de los casos en los que fue consignado el contenido de las urnas funerarias santamarianas, el mismo consiste de huesos de párvulos.

\section{REFERENCIAS}

AcuTo, F., 2007. Fragmentación versus integración comunal Repensando el Período Tardío del Noroeste Argentino. Estudios Atacameños 34: 71-95.

Ambrosetti, J., 2011. El bronce en la región Calchaquí. Buenos Aires Facultad de Filosofía y Letras, Universidad de Buenos Aires.

Ameghino, F., 1881. La antigüedad del hombre en el Plata, Vol. 1. G. Masson \& Igon Hermanos, Eds., París-Buenos Aires.

ARNOLD, D. \& J. YAPITA, 2006. The metamorphosis of heads. Pittsburgh: The University of Pittsburgh Press.

Arnold, D. \& C. Hastorf, 2008. Heads of State. Walnut Creek: Left Coast Press

Boman, E., 1991. Antigüedades de la región andina de la República Argentina y del desierto de Atacama. San Salvador de Jujuy: Universidad Nacional de Jujuy.

Cieza de León, P., 1932 [1553]. La crónica del Perú. Madrid: Espasa Calpe.

1943 [1871]. Del señorío de los Incas. Buenos Aires: Solar.

Descola, P., 1992. Societies of Nature and the Nature of Society. En Conceptualizing Society, A. Kuper, Ed., pp. 107-126. London: Routledge.

— 2012. Más allá de naturaleza y cultura. Buenos Aires: Amorrortu Editores.

Donnan, C. B., 2008. Moche Masking Traditions. En The Art and Archaeology of the Moche, S. Bourget \& K. L. Jones, Eds., pp. 67-80. Austin: University of Texas Press.

Donnan, C. B.; D. A. ScotT \& T. Bracken, 2008. Moche Forms for Shaping Sheet Metal. En The Art and Archaeology of the Moche. S. Bourget \& K. L. Jones, Eds., pp. 113-128. Austin: University of Texas Press.
GARCILASO DE LA VeGA, I., 1941-1943 [1609]. Los comentarios reales de los incas, Primera Parte, Tomo I. Lima: Librería e Imprenta Gil, S.A.

GonzÁlez, A. R., 1974. Arte, estructura y arqueología. Buenos Aires: Ediciones Nueva Visión.

1991-1992. A cuatro décadas del comienzo de una etapa. Apuntes marginales para la historia de la antropología argentina. Runa 20: 91-110.

— 1998. Cultura La Aguada. Arqueología y diseños. Buenos Aires: Filmediciones Valero.

GoretTI, M., 2006. Tesoros precolombinos del noroeste argentino. Buenos Aires: Fundación Centro de Estudios para Políticas Públicas Aplicadas.

Guamán Poma de Ayala, F., 1988 [1516]. Primer nueva corónica y buen gobierno. México, D. F.: Siglo XXI.

HaBer, A., 1995. Supuestos teórico-metodológicos de la etapa formativa de la arqueología de Catamarca (1875-1900). Publicaciones CIFFYH 47: 31-54.

Hocquenghem, A. M., 2005. Sacrificios y calendario ceremonial en las sociedades de los Andes centrales. En Chamanismo y sacrificio. Perspectivas arqueológicas y etnológicas en sociedades indígenas en América del Sur. J. P. Chaumeil, R. Pineda Camacho \& J. F. Bouchard, Eds., pp. 75-104. Bogotá: Banco de la República - Instituto Francés de Estudios Andinos.

Hodder, I., 1993. The narrative and rhetoric of material culture sequences. World Archaeology 25 (2): 268-282. London: Routledge.

IsBell, W., 1997. Mummies and Mortuary Monuments: A postprocessual prebistory of Central Andean Social Organization. Austin: University of Texas Press.

LÉvi-STrauss, C., 1958. Antropología estructural. Buenos Aires: Eudeba.

MARChEGIANI, M., 2008. Estilo y cronología. Los cambios en la cerámica funeraria de Rincón Chico entre los siglos x y XVII DC. En Estudios Arqueológicos en Yocavil, M. Tarragó \& L. González, Eds., pp. 128-175. Buenos Aires: Asociación de Amigos del Museo Etnográfico.

Martínez Sarasola, C., 2004. El círculo de la conciencia. Una introducción a la cosmovisión indígena americana. En El lenguaje de los dioses. Arte, chamanismo y cosmovisión indigena en Sudamérica, A. M. Llamazares \& C. Martínez Sarasola, Eds., pp. 21-66. Buenos Aires: Biblos.

Mayer, E. F., 1986. Armas y herramientas de metal prehispánicas en Argentina y Chile. Materialen zur Allgemeinen und Vergleichenden Archäologie, Band 38. München: Verlag C. H. Beck.

Molina, C. DE, 1959 [1573]. Ritos y Fábulas de los Incas. Argentina: Editorial Futuro

Murúa, M. DE, 2008 [1590]. Historia general del Pirú. Facsimile of Paul Getty Museum MS. Ludwig XIII. Los Angeles: Getty Research Institute.

NASTRI, J., 2008. La figura de las largas cejas de la iconografía santamariana. Chamanismo, sacrificio y cosmovisión calchaquí. Boletín del Museo Chileno de Arte Precolombino 13 (1): 9-34.

- 2009. La noción de transformación en arqueología antropológica y la interpretación del simbolismo santamariano. En Perspectivas actuales en arqueología argentina, R. Barberena, K. Borrazo \& L. Borrero, Eds., pp. 91-120. Buenos Aires: Imicinu. 2010. Begin making sense. Estilos de época y géneros discursivos tardíos en los Andes Meridionales. En Arqueología argentina en el Bicentenario de la Revolución de Mayo, Tomo II, R. Bárcena \& H. Chiavazza, Eds., pp. 845-850. Mendoza: CONICET-INCIHUSA.

Nastri, J.; L. Stern Gelman \& L. Tulissi, 2009. Símbolos de poder en el contexto de una sociedad pre-estatal: Indicios en el arte mortuorio Calchaquí. En Parentesco, patronazgo y Estado en las sociedades antiguas, M. Campagno, Ed., pp. 297-340. Buenos Aires: Editorial de la Facultad de Filosofía y Letras, Universidad de Buenos Aires.

NAstri, J.; F. Schaefers \& V. Coll Moritan, 2010. Deconstruyendo la secuencia agroalfarera del NOA. Del Medio al Intermedio Tardío en Morro del Fraile, Sierra del Cajón (provincia de Catamarca). En Arqueología argentina en el Bicentenario de 
la Revolución de Mayo, Tomo III, R. Bárcena \& H. Chiavazza, Eds., pp. 1161-1167. Mendoza: CONICET-INCIHUSA.

Nastri, J.; V. Coll Moritan \& C. Belotti López de Medina, 2011. Los inicios del Intermedio Tardío en la Sierra del Cajón (provincia de Catamarca). Avance de las investigaciones en Morro del Fraile. Estudios sociales del NOA. San Salvador de Jujuy: EDIUNJU (en prensa).

Nelson, B., 1995. Complexity, hierarchy and scale: A controlled comparison between Chaco Canyon, New Mexico, and La Quemada, Zacatecas. American Antiquity 60 (4): 597-618.

NielSen, A., 2006. Plazas para los antepasados: descentralización y poder corporativo en las formaciones políticas preincaicas de los Andes circumpuneños. Estudios Atacameños 31: 63-89.

2007. Celebrando con los antepasados. Buenos Aires: Mallku Ediciones.

NúÑez RegueIro, V., 1974. Conceptos instrumentales y marco teórico en relación al análisis del desarrollo cultural del Noroeste argentino. Revista del Instituto de Antropología 5: 169-191.

Pérez de BARRADAS, J., 1954. Orfebrería prehispánica de Colombia. Volumen II: Estilo Calima. Madrid: Banco de la República.

Podestá, C. \& E. Perrota, 1973. Relaciones entre culturas del noroeste argentino. San José y Santa María. Antiquitas 17: 6-15.

Proulx, D., 2006. A Sourcebook of Nasca Ceramic Iconography: Reading a Culture through Its Art. Iowa: University of Iowa Press.

Raffino, R., 1988. Poblaciones indígenas en Argentina. Buenos Aires: TEA.

Ricoeur, P., 1995. Tiempo y narración. México, D. F.: Siglo XXI.

Rowe, J. R., 1972. El arte de Chavín: Estudio de su forma y su significado. Historia y cultura 6: 249-275.

SCHINDLER, H., 2000. La colección Norbert Mayrock del Perú Antiguo. München: Staatliches Museum für Völkerkunde.
SCHORSh, D.; E. Howe \& M. T. Wypyski, 1996. Silvered and gilded copper metal work from Loma Negra: Manufacture and aesthetics. Boletín del Museo del Oro 41: 145-163, Bogotá.

Segre, C., 1985. Principios del análisis del texto literario. Barcelona: Crítica.

Sempé, M. C.,1999. La cultura Belén. En Actas del XII Congreso Nacional de Arqueología Argentina, Tomo II, pp. 250-258, La Plata.

Steimberg, O., 1993. Semiótica de los medios masivos. Buenos Aires: Editorial Atuel.

Stern Gelman, L., 2010. Atributos de poder y estatus en la iconografía de las urnas santamarianas. Consideraciones preliminares para su estudio. En Arqueología argentina en el Bicentenario de la Revolución de Mayo, Tomo V, R. Bárcena \& H. Chiavazza, Eds., pp. 2033-2037. Mendoza: Conicet-Incinusa.

TARRAGó, M., 2000. Chacras y pukara. Desarrollos sociales tardíos. En Los pueblos originarios y la Conquista. Nueva historia argentina, M. Tarragó, Ed., pp. 257-300. Buenos Aires: Editorial Sudamericana.

TARTusi, M. \& V. NúÑez Regueiro, 1993. Excavación de un montículo ceremonial tardío. Publicaciones del Instituto de Arqueología 2 (1 Investigaciones): 3-18.

Tucshingam, A. D., 1976. Gold for the Gods. Catálogo de exhibición. Toronto: Royal Ontario Museum.

VELANDia, C. A., 2005. Iconografía funeraria en la cultura arqueológica de Santa María, Argentina. Olavarría: Inculpa.

WeBer, R., 1978. A seriation of the late prehistoric Santa María culture of Northwestern Argentina. Fieldiana Anthropology 68: 49-98. 1981. An analysis of Santa María urn painting and its cultural implications. Fieldiana Anthropology 2, nueva serie: 1-32. 